\title{
Reduplication in Abui: A case of pattern extension
}

\author{
$\operatorname{Marian}_{\text {Klamer }^{1}}\left(\mathbb{C}_{0} \cdot\right.$ George Saad $^{1,2}$
}

Received: 13 August 2018 / Accepted: 10 October 2020 / Published online: 30 October 2020

(C) The Author(s) 2020

\begin{abstract}
This paper studies the effect of ongoing contact on the Abui reduplication system. Abui, a Papuan indigenous minority language of eastern Indonesia, has been in contact with the regional lingua franca, Alor Malay (Austronesian), for around 5060 years. Throughout this period, contact with Alor Malay has affected different age groups in different ways across various levels of grammar. Here we compare Abui reduplication across four age groups: (pre)adolescents, young adults, adults, and elders, and show how the function and distribution of reduplication in the Abui spoken by younger speakers is affected by a combination of morphological PAT borrowing and lexical borrowing from Alor Malay. The changing patterns are first applied to the domain in which the two languages overlap: existing Abui verb reduplications become more Alor Malay-like with respect to their function, form, and productivity. The borrowing of an additional function of reduplication is analyzed as a type of complexification in Abui, while at the same time, Abui reduplication itself is demonstrated to also show simplification in terms of form. We argue that this change is induced by decades of stable bilingualism, and is further enhanced by the fact that reduplication is a universal morphological operation and can emerge spontaneously in language contact situations. Thus, the emerging trends reported here are explained by both borrowing from Alor Malay as well as incomplete acquisition of Abui.
\end{abstract}

Keywords Papuan · Austronesian · Reduplication · Pattern extension · Pattern borrowing

\footnotetext{
M. Klamer

m.a.f.klamer@hum.leidenuniv.nl

G. Saad

george.6.saad@gmail.com

1 Leiden University, Leiden, Netherlands

2 University of Amsterdam, Amsterdam, Netherlands
} 


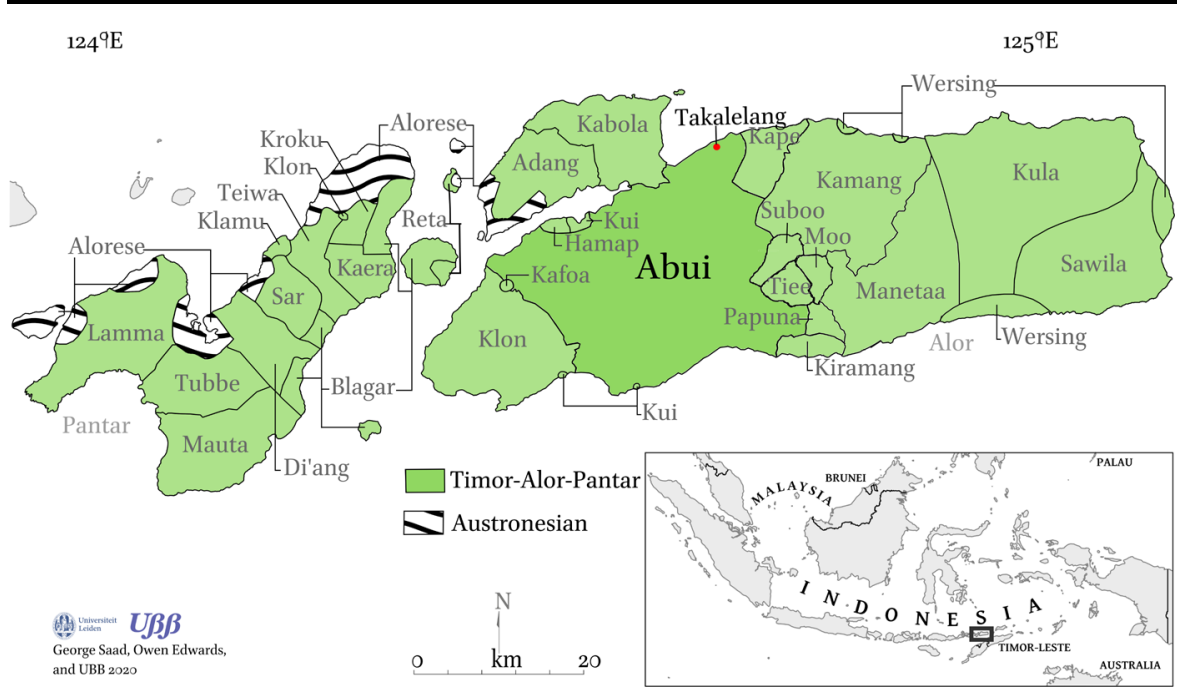

Fig. 1 Map of indigenous languages of Alor and Pantar (Color figure online)

\section{Introduction}

This paper investigates the effect of on-going contact on the Abui reduplication system by Alor Malay. Abui is a Papuan language (of the Timor-Alor-Pantar family, henceforth TAP), spoken on Alor island in eastern Indonesia, see Fig. 1. It is an indigenous minority language which has been in contact with the regional lingua franca, Alor Malay (Austronesian), for around 50-60 years (Kratochvíl 2007; Saad 2020a). Throughout this period, contact with Alor Malay has affected different age groups in different ways across various levels of grammar. In this paper, we compare Abui reduplication across four age groups: (pre)adolescents, young adults, adults, and elders; and show how contact with Alor Malay has led to the extension of a pattern (henceforth PAT extension), namely the reduplication system, in Abui.

In many languages, clear-cut instances of PAT borrowing have been attested (cf. Gardani 2020 and references therein). However, fewer studies have focused on the effects of contact on morphological patterns that are overlapping between languages. This means investigating a pattern that is already shared between language A and language $\mathrm{B}$, but whose abstract properties, such as functions, processes, and distributions are different. In such situations, borrowing of these abstract features can also take place (see Heine and Kuteva 2005; Backus et al. 2011). Indeed, as Matras and Sakel (2007b:17) argue, PAT borrowing "[may be] facilitated by a pivot common to both languages". The transfer of reduplication from Alor Malay to Abui discussed in this paper is one such example.

Reduplication is a word formation process where a part or a whole of a word is doubled. It is found in a large number of the world's languages (Hurch 2005). Reduplication is found in both Abui and Alor Malay; however, there are some key differences. In Alor Malay, reduplication is distributed across open parts-of-speech, incorporates a wide range of functions, and is highly productive. In Abui, reduplica- 
tion has a narrower scope and is less productive than it is in Alor Malay. For example, it applies to fewer parts-of-speech, and within those where it does apply, such as verbs, it does not apply systematically-it is sometimes dispreferred to other verbal strategies used to mark similar functions. In addition, Alor Malay verbal reduplication encodes a wider range of notions including casualness, a notion typically not found in Abui reduplication. There are also more restrictions on Abui reduplication in terms of form, while Alor Malay simply applies total reduplication.

In order to investigate ongoing language contact as it relates to the reduplication system, this paper compares the use of reduplication across four age groups of Abui speakers. We argue that the reduplication patterns of Abui are being expanded under influence from Alor Malay. Due to the dominance of Alor Malay, the reduplication system of young Abui speakers is converging with the system in Alor Malay, and the observed change applies first and foremost to the domain where there is structural overlap between the reduplication patterns in both languages, i.e. verbs.

Using an Abui corpus which includes data from a wide range of speakers (Saad 2019a, see Sect. 5), we use frequency data to document several tendencies of emergent PAT borrowing and lexical borrowing of reduplicated forms (the latter of which will henceforth be referred to as 'loan reduplication') across the age groups. In addition, some instances of nonce borrowings are discussed, also known as nonce replications (Backus et al. 2011). Nonce replications here refer to constructions used by younger speakers which only appear between once and three times in the corpus. While they are idiosyncratic and might never be produced again, if they are indeed propagated and used again, then they may reflect the incipient stages of PAT borrowing (Backus et al. 2011). In this study, it is argued that the nonce instances of reduplication reflect an increased productivity of the feature.

The paper is organized as follows. Section 2 introduces the sociolinguistic setting. Section 3 discusses reduplication from a typological and contact perspective, while Sect. 4 describes the function and distribution of reduplication in Abui (Sect. 4.1) and Alor Malay (Sect. 4.2), respectively. Section 5 discusses the materials and methods used in the present study. In Sect. 6, we analyse the data by discussing four ways in which younger speakers have been modelling their use of reduplication on the types found in Alor Malay: they (i) replace classic Abui parallel serial verb constructions by verb reduplications (Sect. 6.1); (ii) apply the semantic notion of 'casualness' or 'aimlessness' that is found in Alor Malay reduplications on Abui reduplications (Sect. 6.2); (iii) expand Abui reduplication to new domains where older speakers do not use reduplication (Sect. 6.3); and (iv) borrow reduplicated forms from Alor Malay (Sect. 6.4). Section 7 sumarizes and discusses the findings, and Sect. 8 presents a conclusion.

\section{Sociolinguistic setting}

Abui is the largest indigenous Papuan (TAP) language spoken on the islands of Alor and Pantar. The variety studied here is the Takalelang dialect, which is also the most well documented and described one (Delpada 2016:201; Kratochvíl 2007, 2011, 2014a; Perono Cacciafoco et al. 2015; Saad 2020a; Saad et al. 2019). 
The Abui speech community of Takalelang is comprised of three main speech varieties: Abui, Alor Malay, and Indonesian. Abui is the indigenous minority language. Alor Malay is the local variety of Malay used on Alor as a lingua franca between speakers of the many different local languages. Indonesian is the national language of Indonesia, that is often considered a more formal variety of spoken Alor Malay. While Alor Malay shares many lexical similarities with Indonesian, and both languages are typically alternated or mixed in a basilect-acrolect fashion, the two varieties have very different histories. Indonesian was only introduced into the Abui area in the mid-1960s, with the establishment of Indonesian primary schools. Before that time, Alor Malay was already in use, ${ }^{1}$ but the area in central Alor where Abui is spoken remained largely unexposed to it until after World War II. ${ }^{2}$ This speech community configuration of a local language, a local Malay variety, as well as standard Indonesian is common throughout (eastern) Indonesia (Paauw 2008). ${ }^{3}$

Abui is typically used by adults for everyday communication as well as for matters related to adat 'local customs'. Alor Malay is used to communicate with other ethnic groups as well as with Abui children. It is also used among children and youngsters who consider it a more novel and hip language than Abui. Indonesian is limited to formal domains, such as governmental gatherings, church sermons, and media. In Takalelang, Alor Malay is much more widely known and spoken than Indonesian because of Indonesian's limited domain, and because many (older) speakers did not complete their schooling. As such, this paper focuses on the influence of Alor Malay on Abui as, overall, Alor Malay is becoming the most widespread language in the community. All speakers in our corpus are fluent in both Abui and Alor Malay.

Over the last fifty years Abui speakers have become increasingly bilingual under the dominance of Alor Malay, especially in coastal villages. This dominance is increased by the fact that Abui is not used in school, and parents were encouraged in the late 1980s and in the 1990s to raise their children in Alor Malay so that they would be able to attend school without difficulty. This meant that many Abui parents

\footnotetext{
${ }^{1}$ It is likely that Malay was introduced to Alor island in several waves, being limited to certain coastal areas for centuries. The first wave included Muslim missionaries who converted the coastal population found in the Bird's Head Peninsula (known as the Alorese) in the late 16th century (Gomang 1993). Then, in the 19th century at latest, various foreign traders had settled in the coastal areas in the Bird's Head of Alor in several migrations (Baron van Lynden 1851; Du Bois 1944:16). These included Makasarese, Butonese, Bugis, Timorese, and Chinese traders, some of whom came from Kupang, a major port and center of trade on Timor island (see Saad 2020b:76 for discussion). Alor Malay is closely related to Kupang Malay but has its own distinct characteristics (Baird et al. n.d.). In turn, Kupang Malay is a nativized Malay variety that has its origin in the Malay that was used in pre-colonial, pre-European trade contacts (Adelaar and Prentice 1996:675; Jacob and Grimes 2003).

${ }^{2}$ Du Bois (1944:17) comments on the situation of Malay in schools in the central highlands of Alor as being desolate, noting that in Atimelang, the Abui village where she did her research, there were only about 20 boys who understood Malay (possibly implying that girls were not attending school).

${ }^{3}$ Generally speaking, the term Malay refers to hundreds of closely related varieties, spoken differently in Malaysia, Brunei, Singapore, and on the many islands of Indonesia (Tadmor 2009). Malay was the name of the language being used in the Dutch East Indies for several hundreds of years. The term 'Indonesian' or Bahasa Indonesia only came into use after Indonesian independence in 1945. Indonesian is also considered a Malay variety, albeit a more standardized one. Alor Malay is the Malay variety spoken on Alor.
} 
initiated a process of language shift to Alor Malay, as they began raising their children in Malay in preparation for school. Thus, the speech community is in a state of transitional bilingualism (Grenoble and Whaley 2006) meaning that, despite everyone being bilingual, older speakers are more dominant in Abui, whereas younger speakers are more dominant in Alor Malay and more heavily affected by it (Saad 2020a). However, despite the fact that children grow up speaking Alor Malay with their parents and peers, as they grow older, they speak Abui in order to participate in adult affairs (Kratochvíl 2007; Saad 2020a).

The language shift in Abui villages is augmented by more general processes of urbanization as well as the practice of schooling children in urban centers away from their home areas. Many Abui adolescents attend senior high school (SMA) and university in towns like Kalabahi or Kupang, where Malay is spoken. However, counterbalancing the dominance of Malay in these towns is the fact that many Abui students in Kalabahi or Kupang live there with relatives in Abui-speaking households, and thus maintain their language in diaspora. In addition, recent years have shown a trend that young adult Abui who settle back into their home community and start a family there, use Abui rather than Malay in their community networks. This has resulted in a situation where children are brought up speaking Malay to their parents and peers, but as they grow older and take on a more leading role in the community, their social networks expand and they start using Abui a lot more frequently.

Because of these developments, this paper divides the speech community into four groups: (pre)adolescents ( 9 years to 16 years), young adults (17 years to 25 years), adults (26 years to 34 years), and elders (40+ years). (Pre)adolescents, young adults, and adults all had at least some Alor Malay in their upbringing, while elders were all raised in Abui. (Pre)adolescents have the least exposure to Abui and are most dominant in Alor Malay. As such, they are expected to show the most influence from Alor Malay on Abui. This is expected to be less so for young adults, who were raised in Alor Malay, but now typically use a mix of Abui and Alor Malay in their daily interactions. With regards to adults, many of them were raised in Abui, but some were raised in Alor Malay, and they have more interactions in Abui with elders, so they are expected to show only a few signs of contact-induced change. Elders are used as the baseline in this study (see Saad (2020b) for further details and discussion).

\section{Reduplication: A typological and contact perspective}

Reduplication is a word formation process in which some portion of a word is doubled. Total reduplication doubles the entire word, including all of its affixes; partial reduplication doubles some morphophonologically characterized subpart of the word, e.g. a syllable, a root, or a stem (Rubino 2005). Total reduplication is illustrated in (1a-b), partial reduplication (of the initial syllable of a stem) is illustrated in (2a-b).

Papuan Malay (Austronesian, Kluge 2014:158)

a. lari 'run'

b. lari lari 'keep running' 
Blagar (TAP, Steinhauer 2014:158)

a. hera 'descend'

b. he hera 'descend further'

Crosslinguistically, reduplication can carry a whole range of meanings. In (1), reduplication marks continuation (Kluge 2014:178), while in (2), it "indicates movement or position further in the same direction" (Steinhauer 2014:158). The meanings associated with reduplication across languages are typically drawn from a limited repertoire with an iconic grounding (Gil and Hurch 2005; Moravcsik 1974). On verbs, adjectives and adverbs, reduplication may be used to denote a variety of meanings such as continued or repeated occurrence of a verbal argument, completion or inchoativity of an event, attenuation or intensity, transitivity (valence, object defocusing) or reciprocity (Li and Ponsford 2018; Rubino 2013). On nouns, reduplication typically confers plurality, distribution, and collectivity. In addition, within the same language, reduplication may also encode several meanings and interpretations (Li and Ponsford 2018). For example, the Austronesian language, Gayo, spoken in Sumatra, uses full reduplication of verbs to express two seemingly contradictory functions: either emphasis or attenuation (Eades 2005). This is also commonly attested in many eastern Malay varieties; with Papuan Malay being one well-documented example (Kluge 2014). On Papuan Malay verbs, for example, reduplication can mark up to seven functions: i) continuation, repetition, and habit, ii) plurality and diversity, iii) intensity, iv) immediacy, v) aimlessness, vi) attenuation, and vii) imitation. In addition, reduplicated phrases can undergo an interpretational shift, i.e. receive an adverbial or nominal reading (Kluge 2014:185). Alor Malay, as described in Sect. 4.2, shares many such properties with Papuan Malay.

The fact that the same reduplication process may be used to express somewhat opposite notions, such as intensity and aimlessness, is quite commonly attested crosslinguistically (Kiyomi 2009; Kluge 2014; Mattes 2007; Moravcsik 2013). This is due to the nature of reduplication, which is to mark that a word is to be understood in an out-of-the-ordinary sense, either by being more or being less in relation to the base (Moravcsik 2013:131). Here, as Kluge (2014:184) points out, the linguistic context is crucial in determining which interpretation is selected.

Reduplication is a crosslinguistically common morphological strategy (Rubino 2013) especially in Austronesian languages (Blust 2013:406) and in TAP languages (Schapper 2017). It has also emerged in many creoles (Bakker and Parkvall 2005). As such, it is argued to be one of the universal combinatory principles governing improvised language behavior (Muysken 2013:716). Muysken argues that the iconic properties of full reduplication, in particular, where words are doubled to mark emphasis and iteration, are commonly attested bilingual optimization strategies.

In addition to-or perhaps due to-its role as basic combinatory principle, reduplication has also been identified as being sensitive to language contact (Ansaldo and Matthews 2004; Evans 2009; Gardani 2018; Wee and Lim 2004). In the few examples in the literature so far, minority languages of Indonesia containing reduplication have converged their systems to match that of the dominant Indonesian lingua franca, either by reducing or by expanding the native system. For example, Tanjung Raden Malay initially had a larger set of reduplication patterns but due to contact with Standard Indonesian and Riau Indonesian, which have less reduplication patterns than 
Tanjung Raden Malay, it reduced its reduplication system according to that of the dominant language (Yanti and Raimy 2010). ${ }^{4}$

In a similar vein, languages that initially had a relatively smaller reduplication system with respect to the dominant lingua franca have expanded their system. This has been observed in the Alor-Pantar archipelago with TAP languages in contact with the dominant lingua franca, Alor Malay. Kafoa, one of Abui's closest relatives, appears to have also borrowed a reduplication pattern from Alor Malay, namely nominal reduplication to mark plurality (Baird 2017). This is illustrated in (3a-b).

Kafoa (Baird 2017:67)
a. kan 'child'
b. kan $\sim$ kan 'children'

In addition, the notion of aimlessness and casualness (discussed for the closely related Papuan Malay in Kluge (2014) and for Alor Malay in Sect. 4.2) also appears to be calqued from Alor Malay to another Alor-Pantar language, Reta (Willemsen 2020) as shown in examples (4a-d). This pattern resembles Malay $d u d u k \sim d u d u k$ 'sitting around' and jalan jalan 'take a walk; travel; walk around aimlessly'.

Reta (Willemsen 2020:201)
a. miha 'sit'
b. miha miha 'sitting; sitting around'
c. lamal 'walk'
d. lamal lamal 'take a walk; travel'

As we shall see in Sect. 6, a similar process is also taking place in Abui. Section 4 describes the reduplication systems in Abui and Alor Malay, showing key similarities and differences in the systems.

\section{A comparison of reduplication in Abui and Alor Malay}

This section provides a detailed description of the Abui and Alor Malay reduplication systems (Sect. 4.1 and Sect. 4.2, respectively) and a comparison of their similarities and differences (Sect. 4.3).

\subsection{Reduplication and verb serialization in Abui}

Abui reduplicates verbs, numerals, and question words, but not nouns. Verbal reduplication is one strategy used in Abui to mark intensity, continuity, and repetition of events (see Sect. 4.1.1). Reduplication is currently the more productive strategy. However, not all verbs appear to favor reduplication. For certain verbs, older speakers prefer using a strategy known as parallel verb serialization, discussed in Sect. 4.1.2.

\footnotetext{
${ }^{4}$ Note that local Malay varieties play different roles in contact situations in Indonesia. In the study by Yanti and Raimy (2010), Tanjung Raden Malay is the indigenous minority language that is dominated by the majority languages of wider communication, Standard Indonesian and Riau Indonesian. In the contact scenario described in the present paper, Alor Malay is the local dominant majority lingua franca.
} 


\subsubsection{Abui reduplication}

While nouns are not productively reduplicated in Abui, ${ }^{5}$ verbal reduplication is very common. Different types of verbs can be reduplicated, including intransitive and transitive verbs, active and stative verbs (most Abui property words fall into this class), and morphologically simple and complex verbs. The most common function of verbal reduplication in Abui is to mark intensity, continuation, or repetition of an event or state denoted by the verb (described as "increased degree, extension, or impact" (Kratochvíl 2007:274)). A less common, yet widespread function includes gradual change, which is available on stative verbs (Kratochvíl and Delpada 2019). In terms of form, Abui verb reduplication typically involves the stem only, while aspectual suffixes and pronominal prefixes (the only affix types found on the verb) are not reduplicated (with one exception, discussed below).

An illustration of the reduplication of a simple intransitive verb is given in (5). The stem laak 'walk' is reduplicated, while the perfective suffix $-i$ is not part of the reduplication. Reduplication here marks increased intensity. ${ }^{6}$

$\begin{array}{llllll}\text { Ama } & \text { nuku } & \text { do } & \text { laak } \sim \text { laak-i } & \text { ba } & \text { we. } \\ \text { person } & \text { one } & \text { PROX } & \text { RDP } \sim \text { Walk-PFV } & \text { LNK } & \text { go }\end{array}$

$[\mathrm{SS} .48 \mathrm{M} .70]^{7}$

The reduplication of stative verbs is illustrated in (6a-c). These examples show the stative verb falaaka 'be bright' in (6a), which is inflected for aspect in (6b) and reduplicated in (6c) to express increased degree.
a. $N a$
lampu falaak-a
he-wahai.
1SG.AGT lamp be.bright-STAT 3.LOC-look.at
'I see a bright lamp.'
b. Bumi wan falaak-da.
earth already be.bright-INCH.IPFV
'It's already dawn.' (lit. 'Earth has already become bright')
c. Bumi wan falaak falaak-da.
[FN.26M]
earth already RDP be.bright-INCH.PFV
'It's already morning.' (lit. 'Earth has already become very bright')

[FN.26M]

On intransitive stative verbs, reduplication may also be used to mark 'gradual change' as shown in examples (7)-(8). In these constructions, stative verbs (including those

\footnotetext{
${ }^{5}$ There are some lexicalized reduplications of nouns such as luka luka 'monkey' which have a base that is not used independently (*luka is not an Abui word).

${ }^{6}$ It is common to combine reduplication of the manner verb laak 'walk' with verbs encoding the path or direction, such as we 'go (from here)' and $m e$ 'come (here)'.

${ }^{7}$ Every example taken from the Saad corpus is referenced by a code that traces it to its original recording, stored at The Language Archive (Saad 2019a). The codes give information on a) the genre of the recording, b) the age and gender of the speaker, and c) the unique identifier of the recording. The three genres listed here include: SS: Surrey Stimuli video elicitation; CV: conversation; FN: fieldnotes. For instance [SS.48M.70] refers to a Surrey Stimuli video elicitation recording, uttered by a 48-year-old male speaker. The unique identifier of the recording is 70 . All of this information can be found in the file names of the recordings deposited in the Abui corpus.
} 
expressing properties) are typically combined with an inchoative aspect marker $-d a$ / $-d i$ 'INCH.IPFV/PFV'. Only the stem is reduplicated, while the aspectual suffix is not.
a. kiik-a
be.red-STAT
'(be) red'
b. kiik-da
be.red-INCH.IPFV
'turn red'
c. $\quad k i i k \sim k i i k-d a$
RDP be.red-INCH.IPFV
'gradually turning red'

(Kratochvíl and Delpada 2019)
a. yook-a
be.wet-STAT
'(be) wet'
b. yook-da
'turn wet'
be.wet-INCH.IPFV
c. yook $\sim$ yook-da
RDP be.wet-INCH.IPFV
'gradually turning wet'

(Kratochvíl and Delpada 2019)

While in general verbal affixes (pronominal prefixes and suffixes) are not involved in reduplication, there is one exception to this rule. Out of the six pronominal prefix paradigms that Abui has, the patientive paradigm prefixes may be reduplicated alongside the verbal stem, while those of the other paradigms may not (for an overview of Abui pronominal prefix paradigms, see Kratochvíl 2011, 2014a; Saad 2020a). ${ }^{8}$ The six pronominal paradigms are often distinguished by their theme vowel. The distinction between the patientive paradigm (theme vowel /a/) and the reflexive recipient paradigm (theme vowel /o/) is illustrated in examples (9)-(10). In (9a-b) the reduplication of verb stem and patientive pronominal prefix $h a$ - is shown, whereas in (10a-b) the pronominal prefix $d o-$ ' 3 .REFL.REC' is not reduplicated, only the verb stem is.

(9) Patientive paradigm

a. Neeng nuku natet ba pining halak $\sim \boldsymbol{h a - l a k - d a . ~}$

man one stand.PFV LNK field RDP 3.PATN-examine-IPFV

'A man is standing there inspecting the field.'

b. Hedo pi pi-maama he-nala

3.FOC 1PL.INCL.AGT 1 PL.INCL.AL-father 3.AL-thing

la $=n g \quad$ habeeq $\sim$ ha-beeq-da.

$\mathrm{ADV}=\mathrm{ALLA} \mathrm{RDP} \sim 3$.PATN-be.bad-INCH.IPFV

'This here, we are really destroying our esteemed friend's thing.'

[CV.75F.HJ]

${ }^{8}$ Thanks to František Kratochvíl for making this observation. 


\section{Reflexive recipient paradigm}

a.

Neeng nuku [......] do-anang anang-ra.

man one 3.REFL.REC-RDP talk-IPFV

'A man [is lying on his back], having a whole conversation with himself.'

[SS.43F.25]

b.

Neeng nuku oro mit ba dom- ${ }^{9}$ pang $\sim$ pang.

man one DIST.LVL sit LNK 3.REFL.REC:in-RDP think

'A man is sitting there, pondering (something).'

[SS.43F.25]

This shows how inflectional morphology can interact with the form of reduplication, implying that speakers must be sensitive to the type of morpheme being attached to the stem while carrying out a reduplication.

Numerals are reduplicated to create distributive numerals, which express notions such as 'one by one' as in (11a), 'two by two' as in (11b), and 'in groups of 27' as in (11c).
a. $\quad \boldsymbol{n u k} \sim \boldsymbol{n u k}-d a$
$\mathrm{RDP} \sim$ one-INCH.IPFV
'one by one'
$\begin{array}{ll}\text { b. } & \text { a-pong ayoq } \sim \text { ayoq-da. } \\ \text { 2SG.INAL-face RDP } \sim \text { two-INCH.IPFV }\end{array}$
'You have a faceache.' (lit. 'Your face goes two by two.') [CV.43F.AH]
c. kar ayoqu wal yeting ayoq $\sim$ ayoq-da
ten two ADD five RDP $\sim$ two-INCH.IPFV
'in groups of 27 '
[FN.26M]

Reduplicated numerals in Abui function as predicates (Abui has no copular verb). As such, they undergo stem alternation and host an inchoative suffix, such as - $d a$ in examples (13a-c). A full list of stem alternations and inchoative aspectual suffixes for the numerals 'one' to 'nine' is presented in Table 1. As shown in the table, reduplicated numeral stems also undergo irregular stem alternation such as sua 'three' > $s u i \sim s u i-d a$ 'three by three'. In addition, the inchoative suffix has several allomorphs $(-d a,-n a,-r a)$. Note also that Abui has a quinary (base-5) system, where the numerals 'seven', 'eight', and 'nine' are compounds containing a form for 'five' in their first position followed by a form reflecting 'two', 'three', and 'four'. In distributive reduplication, only this second element, which carries word stress, is reduplicated, resulting in a type of internal reduplication.

Higher numerals (borrowed from Alor Malay) undergo full reduplication and do not take an aspectual suffix, as in rifi rifi 'in thousands' in (12).

$$
\begin{aligned}
& \text { Ama rifi-rifi } \quad \text { sei } \\
& \text { person } \mathrm{RDP} \sim \text { thousand come.down.IPFV } \\
& \text { 'People came come in thousands [to that place].' }
\end{aligned}
$$

(Kratochvíl 2014b)

\footnotetext{
${ }^{9}$ The additional $/ \mathrm{m} /$ in dom - pangpang in (12) is probably a lexicalized form from an earlier construction involving $m(i)$ 'inside'.
} 
Table 1 Abui cardinals and distributives (Klamer et al. 2017:341-342)

\begin{tabular}{llll}
\hline Number & Cardinal & Distributive & Gloss \\
\hline 1 & nuku & $n u k \sim n u k$-da & 'one by one' \\
2 & ayoqu & ayoq $\sim$ ayok-da & 'two by two' \\
3 & sua & sui $\sim$ sui-da & 'three by three' \\
4 & buti & buk $\sim$ buk-na & 'four by four' \\
5 & yeting & yek $\sim$ yek-na & 'five by five' \\
6 & talaama & talan $\sim$ talan-ra & 'six by six' \\
7 & yeting ayoqu & yeting ayoq $\sim$ ayoq-da & 'seven by seven' \\
8 & yeting sua & yeting sui $\sim$ sui-da & 'eight by eight' \\
9 & yeting buti & yeting buk $\sim$ buk-na & 'nine by nine' \\
\hline
\end{tabular}

Question words may also be reduplicated as in (13), where nala 'what; thing' is reduplicated to mean 'something' or 'whatever'.

\section{We hel=loqu iti nala $\sim$ nala.}

go $\mathrm{ART}=\mathrm{PL}$ lie $\mathrm{RDP} \sim$ what

'Going there, there is something/whatever."

[SS.75F.JH]

To sum up, reduplication is found in Abui verbs, numerals, and question words, but not in other categories such as nouns, adjectives, or adverbs. It is most prominent in verbs where it typically marks intensity and continuity, while it may occasionally also mark gradual change. In Abui, there are formal restrictions on what is reduplicated: typically only the stem is reduplicated; aspectual suffixes are not, and of all the pronominal prefixes, only the patientive prefix may take part in the reduplication. In addition, verbal reduplication appears to be lexicalized and is therefore not entirely productive. This is highlighted in Sect. 4.1.2, which discusses another strategy favored over reduplication to express notions of increased intensity, continuation, and repetition.

\subsubsection{Abui parallel verb serialization}

Abui has a subset of verbs for which reduplication is not considered the optimal strategy to express notions of increased intensity, continuation, and repetition. For some of those verbs, although not all, a strategy involving the use of conventionalized and lexicalized serial verb constructions must be used. This is referred to as 'parallel' serialization (Kratochvíl 2007:357). Parallel serialization is a type of verb serialization where two verbs with synonymous or related meanings (which may also occur on their own) are paired together to convey repetitive events, or events with an increased intensity. One important feature of these constructions is that both verbs in the construction have the same argument structure and are marked by the same pronominal prefix; both verbs index the same participant. Examples of three such constructions are presented in (14)-(16). In (14), the parallel verb pair include -yok '-shake' -tel 'tie together' meaning 'shake back and forth'. Here, the third person patient prefix ha-is used on both verbs ha-yok ha-tel 'shake back and forth' indexing deisi 'her body' in a transitive clause. 
$\begin{array}{ll}\begin{array}{ll}\text { Maayol nuku }[\ldots] d e-i s i=n g & \text { ha-yok } \\ \text { woman one } & \text { 3.REFL.AL }\end{array}{ }^{10} \text {-body=ALLA } & \text { 3.PATN-shake }\end{array}$

ha-tel.

3.PATN-bundle

'A woman shakes her body back and forth.'

[SS.30M.36]

In (15), -lal 'laugh' -baai 'revel' combine to derive the meaning 'burst out laughing'. Here, the reflexive patient prefix $d a$ - is used on both verbs $d a$-lal da-baai 'burst out laughing' to co-index the S argument, maayol nuku 'a woman'.

\section{Maayol nuku donakal mit ba da-lal da-baai.}

woman one 3.ALONE sit LNK 3.REFL.PATN-laugh 3.REFL.PATN-revel

'A woman is sitting by herself and bursts out laughing.'

In (16), the distributive patient prefix $t a$ - is used on the verbs - $f i k$ 'pull' -ber 'pull out', which combine for the meaning 'tugging each other back and forth'. The distributive pronominal prefix ${ }^{11}$ signals a reciprocal relation between the participants (for more information on reflexive and reciprocal constructions, see Saad 2020a:330).

Neeng ayoqu oro ming ta-fik ta-ber

man two DIST.LVL APPL DISTR.PAT-pull DISTR.PAT-pull.out.PFV

'Two men there have been tugging each other back and forth.' [SS.43M.44]

In the corpus used for this study, parallel serializations are used by the older Abui speakers, while the younger speakers mostly use verb reduplications instead, a strategy that older speakers find unacceptable (see Sect. 6).

\subsection{Reduplication in Alor Malay}

Reduplication in Alor Malay bears both differences and similarities with respect to reduplication in Abui. In terms of form, unlike Abui, only full reduplication is found. This is related to the fact that Alor Malay has little productive morphology (Baird et al. n.d.; see also footnote 12). In terms of distribution, full reduplication is more widespread than it is in Abui. It occurs in a larger number of parts-of-speech, is more productive, and also has more functions. Specifically, nouns, verbs, adjectives, question words and numerals can all undergo reduplication.

On nouns, reduplication adds a semantic element to the meaning of the base word. This may be plurality as in (17), collectivity as in (18), and diversity as in (19).

Kemarin ini apa dengan ana $\sim$ ana dong latihan tu ko?
yesterday PROX what with $\mathrm{RDP} \sim$ child ASSOC.PL practice DIST tag

\footnotetext{
${ }^{10}$ Abui has separate prefixes encoding alienable or inalienable possession; and it also distinguishes 'reflexive' versus 'non-reflexive' possession (Saad et al. 2019). In reflexive possession, the possessor in the object NP is bound by the subject NP, and this binding relation is expressed by a dedicated possessor paradigm.

${ }^{11}$ Abui and other TAP languages have pronominals with a 'distributive' function, which refer explicitly to a (noncollective) plurality of human referents (translated into English as 'each (one)'). Distributive pronominals have a referential function, and are distinguished from the distributive numerals derived by reduplication discussed above, which have a predicative function.
} 
'Yesterday, erm, [you had singing] practice with the children, right?'

[CV.24F.DA.AM]

(18) Sepertinya ibu, dia pung tangan

it.looks.like mother $3 \mathrm{SG}$ POSS hand

'It seems like a woman; her hands,

kita lihat ni, ke mama mama begitu.

1PL.INCL look PROX like RDP mother like.that

[if] we look at them, resemble those of moms.'

[SS.25M.30.A]

(19) Daun $\sim$ daun ada banyak di George pung bahu jadi, RDP leaf EXT many LOCA George POSS shoulder so 'There were all sorts of leaves on George's shoulder, so,

ini, Simon datang ko kasi bersi.

PROX Simon come LNK CAUS clean

well, Simon came and cleaned [it].'

[SS.28F.80.AM]

The semantic elements of plurality and diversity can also be seen when reduplication is applied to verbs, where they are interpreted as the repetition, increased intensity, continuation or habituality of events or states. In (20), reduplication of the verb bergerak 'move' marks continuation of the event of moving. ${ }^{12}$

\section{Wa ... ada bergerak $\sim$ bergerak la! \\ EXCLM PROG RDP $\sim$ move \\ EMPH}

'He keeps on moving!'

[CV.9F.MM]

In (21), reduplication of the verb foto 'take photos' expresses an activity of 'taking photos over and over again'. In both (20) and (21), the progressive marker ada (related to the verb $a d a$ 'exist'), is combined with the reduplicated verbs to mark continuation.

Dia ada sengaja foto $\sim$ foto orang tu.

3SG PROG deliberately RDP photograph person DIST

'He's taking many photos of them over and over again on purpose.'

[CV.28M.DA.AM]

Another prominent function of verbal reduplication in Alor Malay is to express doing something in an aimless or casual manner, i.e. without a particular goal (cf. Sneddon et al. 2012; Kluge 2014). In (22), the subject, nyong 'man', is just sitting around casually, not engaging in any other activity and with no particular aim in mind. This is expressed by using the reduplicated form $d u d u k \sim d u d u k$ 'RDP $\sim$ sit'.

12 Unlike other varieties of Indonesian, where ber-functions as a prefix and thus does not take part in the reduplication (as in ber-gerak 'move, ber-gerak gerak 'keep on moving'), Alor Malay has very little productive morphology and verbs with ber-are treated as a unit in reduplication, hence bergerak $\sim$ bergerak rather than *bergerak $\sim$ gerak. 
Ada nyong satu, dia duduk $\sim \boldsymbol{d u d u k}$

EXT man one 3 SG RDP $\sim$ sit

'There's a man, just sitting around.'

[SS.28F.80.AM]

In (23), the reduplicated form of jalan 'walk' implies 'walking around aimlessly', with the adverb terus adding a sense of continuity.

\section{Jalan jalan terus makanya lu lupa to? \\ $\mathrm{RDP} \sim$ walk continuously hence $2 \mathrm{SG}$ forget TAG}

'(You are) continuously going around for no reason; so it's no wonder you forgot, right?'

[CV.28M.DA.AM]

In (24), some further examples of reduplications carrying a notion of aimlessness and casualness are given.

$$
\begin{aligned}
& \text { senyum 'to smile' senyum senyum 'smile for no reason' } \\
& \text { pikir 'think' pikir-pikir 'ponder' } \\
& \text { jalan 'walk' jalan-jalan 'go for a stroll; travel around' } \\
& \text { pegang 'hold (tightly)' pegang-pegang 'hold (loosely)' } \\
& \text { berdiri 'stand' berdiri-berdiri 'standing around (without purpose)' } \\
& \text { duduk 'sit' duduk-duduk 'sitting around, relaxing' [FN.40F] }
\end{aligned}
$$

The interpretation of the meaning element added by the reduplication process depends on the lexical semantics of the base word as well as the combination with other items in the clause (e.g. using the reduplication in a progressive construction with ada 'PROG' as in (21), or combining it with the adverb terus to express continuation as in (23)). In addition, it also interacts with the pragmatic context of the utterance. As a result, the same reduplication may get different interpretations depending on the context where it is used. For example, senyum senyum 'RDP smile' may mark casualness or aimlessness as in 'smile for no reason', but in other contexts it can mark repetition, continuation, or intensity ('smile repeatedly', 'keep on smiling', 'smile a lot').

Adjectives can also be reduplicated to mark intensity. This is illustrated in (25), where the adjectives keras 'strong' and takut 'afraid' are both reduplicated. With the prohibitive jangan, the construction means 'don't be so afraid'.

Omong ko suara keras $\sim$ keras jangan takut $\sim$ takut la! speak LNK voice RDP be.strong PROH RDP be.afraid EMPH 'Speak so that your voice is loud and strong, don't be so afraid!'[SS.23M.6]

Further, similar to Abui, question words, such as apa 'what' or kapan 'when', are reduplicated to derive impersonal pronouns, such as 'whatever' or 'whenever', as shown in (26)-(27).

Saya tida punya apa $\sim$ apa untuk kamu.

$1 \mathrm{SG}$ NEG have RDP what for 2PL

'I don't have anything for you (PL).'

[FN.23F] 
Kapan $\sim$ kapan dia datang di Takpala, di orang Abui $\mathrm{RDP} \sim$ when $3 \mathrm{SG}$ come LOCA Takpala LOCA person Abui 'Whenever/someday she'll come to Takpala, to the Abui people,

baru dia lihat kita na dia senang begitu.

then 3SG look 1PL.INCL COND 3SG happy like.that when she'll see us, she'll be happy.'

[CV.28M.DA.AM]

Alor Malay also reduplicates numerals to derive distributive numerals, which function to express notions such as 'one by one', as in (28).

\section{Dulu OMK ni banyak orang}

past Catholic.youth PROX many person

tapi satu $\sim$ satu su mulai keluar

but $\mathrm{RDP} \sim$ one already start exit

'In the past there were lots of young Catholic Abui, but one by one they've started to leave.'

[FN.23F]

\subsection{Summary: Comparison of reduplication in Abui and Alor Malay}

Reduplication in Abui and Alor Malay bears some similarities as well as some differences. Abui generally reduplicates the stem (with a few exceptions), while Alor Malay reduplicates the whole word. Another difference is that reduplication is less productive in Abui than in Alor Malay. Abui has no nominal reduplication, while Alor Malay marks (associative) plurality, diversity, and collectivity through nominal reduplication. In Abui, reduplication may be applied to many but not all types of

Table 2 Reduplication in Abui and Alor Malay

\begin{tabular}{|c|c|c|}
\hline & Abui & Alor Malay \\
\hline Formal features & $\begin{array}{l}\text { Partial reduplication } \\
\text { (Stem and patientive prefix } \\
\text { reduplicated, other prefixes } \\
\text { and suffixes not reduplicated) }\end{array}$ & Full reduplication \\
\hline \multirow[t]{2}{*}{ Verbs } & $\begin{array}{l}\text { - Marks: intensity, continuation, } \\
\text { repetition }\end{array}$ & $\begin{array}{l}\text { - Marks: intensity, continuation, } \\
\text { repetition, and casual/aimless manner; }\end{array}$ \\
\hline & $\begin{array}{l}\text { - Not entirely productive; lexicalized } \\
\text { for most, but not all, verbs }\end{array}$ & - Entirely productive \\
\hline Nouns & $\mathrm{n} / \mathrm{a}$ & $\begin{array}{l}\text { (Associative) plurality, diversity, } \\
\text { collectivity }\end{array}$ \\
\hline Adjectives / stative verbs & Intensity; gradual change & Intensity \\
\hline Question words & Derives indefinite pronouns & Derives indefinite pronouns \\
\hline Numerals & Marks distribution & Marks distribution \\
\hline
\end{tabular}


verbs, marking intensity, continuation, repetition, and gradual change, while in Alor Malay, reduplication may apply to all verbs and marks intensity, continuation, repetition, and casual/aimless manner. Reduplication of stative verbs and adjectives in Abui marks intensity or gradual change, while in Alor Malay, it only marks intensity. Reduplication of question words appears to work similarly in both languages, deriving indefinite pronouns. Reduplication of numerals also has the same function, namely to encode distributional numerals like 'one by one'. The reduplication features of both languages are compared in Table 2.

\section{Present study: Materials, methods, and hypotheses}

The Abui corpus used for this study contains 30 hours of Abui utterances (see Saad 2019a; 2020a, 2020b), ${ }^{13}$ which include conversational data ( $\sim 5$ hours) and $\sim 25$ hours of responses to video clips known as the Surrey Stimuli (Fedden et al. 2010). Lumping together these two genres, we isolated all the utterances that contained reduplications in Abui. ${ }^{14}$ In total, this amounted to 189 utterances by a total of 60 different speakers, across four age groups (see Table 3). ${ }^{15}$ There were several key advantages of using these two genres. With regards to the responses to video stimuli, we could observe the constructions that various age groups used in response to the same set of stimuli. This allowed for comparability. Conversational data, being more natural and ecologically valid, provides a window into how speakers actually use the language in everyday life. Conversational data was important in discovering nonce utterances. Together, these two genres supplemented one another. The present study compares Abui reduplication as used across four age groups of Abui/Alor Malay bilingual speakers: (pre)adolescents, young adults, adults, and elders. Table 3 illustrates the number of unique speakers producing reduplications, as well as showing the total number of speakers in the corpus. In addition, the far right column lists the number of reduplication tokens found for each of the age groups. These figures give a general idea of how frequently the different age groups produce reduplications.

Examining Table 3, it appears that age is negatively correlated with incidence of reduplication, with younger speakers producing more reduplications. The group

\footnotetext{
${ }^{13}$ The data was not originally intended to elicit reduplication patterns, but was rather aimed at eliciting an Abui bilingual corpus of various age groups from which variable patterns could be detected. Only after recording and transcribing the data, did it become clear that the reduplication patterns showed variability across the age groups which warranted further investigation. In addition, genre was not controlled for in this study.

${ }^{14}$ One may wonder why these two genres were not kept separate and then compared with one another. The reason is that the two genres were not comparable in terms of size, so it made sense to lump them together and compare utterances across groups, rather than add an additional variable of genre as well.

${ }^{15}$ All speakers reduplicated a wide range of verbs: 45 different verb forms were used in the 189 utterances we investigated. The most frequent of these included laak 'walk' (28 tokens), (dom)pang 'think' (26 tokens), halak 'inspect' (15 tokens), and anang 'talk' (11 tokens) used across all age groups. Together, these four verbs accounted for 80/189 utterances. The other 41 verbs had between 1 and 3 tokens. There is thus very little overlap in the verbs that speakers reduplicate. This is especially striking since a large part of the corpus consists of responses to video clips depicting a limited set of 40 events, so that we would expect to see bias towards a limited set of verbs used to describe these clips (see Saad 2020a for further explanation).
} 
Table 3 Participant list for reduplication tokens

\begin{tabular}{lrlll}
\hline Groups & $\begin{array}{l}\text { Age range } \\
\text { in years }\end{array}$ & $\begin{array}{l}\text { N of unique speakers } \\
\text { producing } \\
\text { reduplications }\end{array}$ & $\begin{array}{l}\text { Total N of speakers in } \\
\text { corpus }\end{array}$ & $\begin{array}{l}\text { Total number of } \\
\text { reduplication tokens }\end{array}$ \\
\hline Pre)adolescents & $9-16$ & 20 & 20 & 65 \\
Young adults & $17-25$ & 17 & 21 & 56 \\
Adults & $26-34$ & 15 & 22 & 44 \\
Elders & $40-75$ & 8 & 14 & 24 \\
Total & $9-75$ & 60 & 77 & 189 \\
\hline
\end{tabular}

of (pre)adolescents produced 65 tokens of reduplicated forms, followed by young adults (56 tokens), adults (44 tokens), and elders (24 tokens). The number of unique speakers producing reduplications was also highest in the group of (pre)adolescents (20/20 speakers), followed by young adults (17/21 speakers), and adults (15/22 speakers). Elders had the least (8/14 speakers). This already suggests that there was a higher chance that (pre)adolescents would produce a reduplicated form than the other groups, possibly as a sign that it is becoming more frequent and productive among them. These tendencies are discussed further in Sect. 6.

In order to investigate whether young speakers were reduplicating in ways similar to older speakers, all reduplicated utterances were coded according to function and form. We then compared whether the (pre)adolescents, young adults, and adults, behaved similarly to the group of elders.

In addition to comparing the number of reduplications across speakers, the reduplication utterances of (pre)adolescents, young adults, and adults were presented to elders who provided judgements on whether they thought an utterance containing a reduplication was acceptable to them, or not; and if not, what the acceptable equivalent utterance would be. These judgements are not part of the original data set, but were elicited after the initial data had been recorded and transcribed (they are indicated as 'corrections' in the text). Therefore, our method to showcase the existence of age-related differences in use of reduplications here involves i) giving an example of a reduplication utterance by a younger speaker, ii) providing the judgement of that utterance by an older speaker, iii) giving the equivalent utterance produced by the older speaker, showing how it differs in function or form with the younger speaker's utterance.

Combining metalinguistic judgements and utterances by older speakers to highlight differences in usage provides stronger evidence in support of ongoing innovation in the system. This method is especially useful when working with small corpora like ours that do not contain sufficient tokens to conduct statistical analyses on. In addition, because the differences in meanings are so nuanced and there do not appear to be clear-cut rules as to which verbs can or cannot be reduplicated in Abui (see Sect. 4.1), it is even more important to recruit native elder speakers to evaluate the reduplications. Finally, because indigenous minority languages are known to have significant variation due to the lack of a 'standardized' language, using speaker judgements is a useful means to tap into the boundaries of acceptable variation (Nagy 2009). 
Another important part of our data set included utterances containing parallel serializations (see Sect. 4.1.2). These constructions mark similar functions to reduplication (increased intensity, continuation and repetition) but are prefered to reduplication by a certain subset of verbs. From the Abui corpus, we thus extracted 20 utterances containing parallel serializations. They were collected to compare which strategy (reduplication or parallel serialization) was preferred among which age group.

In order to investigate whether the age-related differences were related to contact with Alor Malay, we also extracted reduplication utterances from a small Alor Malay corpus (Saad 2019b). This was important in understanding the Alor Malay system more concretely. It was used as the basis for the descriptive section in Sect. 4.2. We used this descriptive information to compare Alor Malay and Abui and see whether there was evidence of shared patterns. Such shared patterns are hypothesized to be contact-induced, especially if they correlate with age-related variation. If the Abui of younger Malay-dominant age groups shows a higher instance of patterns shared with Alor Malay, while the Abui spoken by elders who were brought up monolingually shows fewer or no such shared patterns, this suggests that the patterns of the younger speakers are borrowed from Alor Malay. The Alor Malay corpus contains 2 hours of data: 1:40 hours of responses to the Surrey Stimuli (Fedden et al. 2010) and 20 minutes of conversational recordings (see Saad 2020b:150). In addition, we compiled reduplications from the code-switches to Alor Malay that were present in the Abui corpus. In total, we compiled 93 Alor Malay utterances with reduplications by a total of 10 Alor Malay-Abui bilinguals aged 9-42.

After compiling all of this data, we examined the 189 Abui reduplication utterances and coded them according to two main categories: i) Native reduplications and ii) Contact-induced reduplications. Native reduplications refer to reduplications which were deemed to be of standard Abui usage. They follow the same formal and functional characterisitcs of the reduplication produced by elders and were also deemed acceptable (grammatical) by older speakers. Contact-induced reduplications were considered to be deviant from the standard by the group of elders, and related in form or function to Alor Malay. We found three types of contact-induced reduplications involving PAT extension and one type of lexical borrowing. PAT extension involve: a) the replacement of parallel serializations by reduplication, ii) reduplicating with the notion of aimlessness, c) expanding reduplication to new domains. Lexical borrowing involves the insertion of reduplicated utterances from Alor Malay.

\section{Borrowing of reduplication from Alor Malay into Abui}

In this section, we discuss how reduplication is borrowed from Alor Malay into Abui. First, we describe three ways in which young bilinguals engage in PAT extension, borrowing patterns of reduplication into Abui under influence of Alor Malay: (i) by replacing parallel serializations with reduplications (Sect. 6.1); (ii) by using reduplication to mark the notion of aimlessness (Sect. 6.2), and (iii) by expanding reduplication to new structural domains (Sect. 6.3). Finally, in Sect. 6.4 we also present instances of Alor Malay reduplications being inserted in Abui. Next, in Sect. 6.5, we summarize the token frequencies of these four types of borrowing for the four age groups. 


\subsection{PAT extension I: The replacement of parallel serializations by reduplications}

As discussed in Sect. 4.1.2, Abui employs parallel serializations as one of its two major strategies to express increased intensity, continuation, and repetition of events. Although Abui lacks a standard grammatical norm, there are two indications that Abui speakers consider parallel serialization a more preferred pattern for certain predicates than verb reduplications. First, when older speakers want to mark increased intensity, continuation, and repetition on certain predicates, they always use parallel serialization instead of reduplicated constructions; second, when presented with utterances involving reduplicated forms of those predicates, they explicitly reject them as sounding unacceptable.

In this section, we review the younger speakers' tendencies to use reduplicated constructions instead of parallel serializations, and compare them with corrections provided by older speakers, complemented by naturally produced utterances by older speakers. Tokens are presented in Table 5 at the end of the section. Specifically, the three predicates listed in Table 4 corresponded to three distinct video clips: shakeREPETITION, laugh-INTENSITY, tug-CONTINUATION. The table clearly shows that older speakers preferred parallel serializations, while younger speakers preferred reduplications. (Pre)adolescents (aged 9-16), especially, seem to prefer reduplicated constructions over parallel serializations when faced with the same video clip stimulus.

These constructions are illustrated in (29)-(31). The reduplications uttered by the younger speakers in the (a) examples are semantically equivalent to the parallel serializations uttered by the older speakers in the (b) examples. However, while (pre)adolescents would rather use reduplications to encode the intensity, continuation, or repetition of events, the older speakers prefer to express this by parallel serializations.

In (29a), in response to a particular clip from the Surrey Stimuli which shows people that are dancing, a 13-year-old speaker reduplicates ha-yok '3.PATN-shake' to mark intensity and repetition. From (29b), derived from judgement data, and (29c), derived from production data, it is clear that older speakers have a preference for using the parallel serialization ha-yok ha-tel '3.PATN-shake 3.PATNtie.together'.

Table 4 Parallel serialization vs. reduplications

\begin{tabular}{lll}
\hline Responses to clips and translations & Older speakers & Younger speakers \\
\cline { 3 - 3 } & Parallel serializations & Reduplications \\
\hline shake-REPETITION & - yok -tel & - yok $\sim$-yok \\
'shake (s/t) back and forth' & - shake -tie.together & RDP $\sim$ shake \\
laugh-INTENSITY & $-l a l-$ baai & $-l a l \sim-l a l$ \\
'burst out laughing' & - laugh -revel & RDP laugh \\
tug-CONTINUATION & $-f i k-$ bel/r & $-f i k \sim-f i k$ \\
'keep tugging back and forth' & - pull -pull.out & RDP $\sim$ pull \\
\hline
\end{tabular}


a. 13-year-old female ((Pre)adolescent)

Di de-raala hayok hayok ba di taa.

3.AGT 3.REFL.AL-throat RDP 3.PATN-shake LNK 3.AGT sleep.IPFV

Intended: 'He shakes his neck back and forth and then sleeps.'

[SS.14F.55]

b. Correction of (29a) by a 40-year-old female (Elder)

Di da-wata=ng ha-yok ha-tel.

3.AGT 3.REFL.INAL-neck=ALLA 3.PATN-shake 3.PATN-tie.together

'He shakes his neck back and forth.'

[FN.40F]

c. 30-year-old male (Adult)

De-isi=ng ha-yok ha-tel.

3.REFL.AL-body=ALLA 3.PATN-shake 3.PATN-tie.together

'He shakes his body back and forth.'

[SS.30M.36]

In (30a), a 16-year-old speaker marks intensity on the verb da-lal '3.REFL.PATlaugh' through reduplication. Both (30b) and (30c) show that older speakers (elders) have a preference for the parallel serialization da-lal da-baai '3.REFL.PAT-laugh 3.REFL.PAT-revel'.

a. Utterance by 16-year-old female

Maayol nuku o miti ba donakala o

woman one MED sit.PFV LNK 3.ALONE MED

dalal $\sim$ da-lal

RDP 3.REFL.PAT-laugh

Intended: 'A woman is sitting and laughing really hard on her own.'

[SS.16F.17]

b. Correction of (30a) by a 40-year-old female

Maayol nuku o miti ba donakal walao

woman one MED sit.PFV LNK 3.ALONE only MED

da-lal

da-baai.

3.REFL.PAT-laugh 3.REFL.PAT-strike

'A woman is sitting and laughing really hard on her own.' [FN.40F]

c. Utterance produced by a 48-year-old male

Maayol nuku donakala mit ba da-lal

da-baai.

woman one 3.ALONE sit LNK 3.REFL.PAT-laugh 3.REFL.PAT-revel

'A woman is sitting and laughing really hard.'

[SS.48M.70]

In (31a), a similar case is shown with the verb ha-fik '3.PATN-pull' being reduplicated by a 22-year-old speaker to derive the meaning 'tug'. Similar to the examples above, the correction in (31b) provided by a 40 -year-old speaker, complemented by the utterance in $(31 \mathrm{c})$ together indicate that older speakers prefer parallel serializations. In (31c), the distributive prefix $t a$ - encodes the reciprocity of the event. 
Table 5 Token frequencies for PAT extension I: Replacement of parallel serializations

\begin{tabular}{lllll}
\hline Groups & Speakers & $\begin{array}{l}\text { Parallel serialization } \\
\text { target }\end{array}$ & $\begin{array}{l}\text { Reduplication (PAT } \\
\text { extension I) }\end{array}$ & $\begin{array}{l}\text { Parallel } \\
\text { serialization }\end{array}$ \\
\hline (Pre)adolescents & 20 & 5 & 4 & 1 \\
Young adults & 17 & 4 & 1 & 3 \\
Adults & 15 & 9 & 1 & 8 \\
Elders & 8 & 7 & 0 & 7 \\
Total & 60 & 25 & 6 & 19 \\
\hline
\end{tabular}

a. Utterance by 22-year-old male

Neeng nuku de-feela ha-tang hafik $\sim \boldsymbol{h a - f i k . ~}$

man one 3.REFL.AL-friend 3.INAL-hand RDP 3.PATN-pull

'A man is tugging on his friend's hand.'

[SS.22M.38]

b. Correction of (31a) by 40-year-old female

Neeng nuku de-feela ha-tang ha-fik

man one 3.REFL.AL-friend 3.INAL-hand 3.PATN-pull

ha-bel.

3.PATN-pull.out.IPFV

'A man is tugging on his friend's hand.'

[FN.40F]

c. Utterance by 48 -year-old male

Neeng ayoqu oro ming ta-fik ta-ber

man two DIST.LVL APPL DISTR.PAT-pull DISTR.PAT-pull.out.PFV

ba me do.

LNK come PROX

'Two men there have been tugging each other back and forth, coming our way.'

[SS.48M.70]

The token frequencies for reduplication utterances where parallel serialization would be expected are listed in Table 5. The column 'Parallel serialization target' represents contexts where we expect that 'intensity' is marked on a verb that is typically used in a parallel serialization. (Pre)adolescents produce five of these targets, using reduplication in four of them, while using parallel serialization in only one. Young adults produce four such targets, using reduplication in one of them, while using parallel serialization in three. Adults produce nine such targets, using reduplication in one of them, while using parallel serialization in eight. Elders produce seven targets, and use parallel serialization in all seven. This suggests that (pre)adolescents are most likely to use reduplication instead of parallel serialization, although two instances were also found in young adults and adults combined. ${ }^{16}$ These results show that while PAT borrowing of reduplica-

\footnotetext{
${ }^{16}$ Alor Malay also has serial verb constructions, so one question that might come to mind is whether the verb serialization strategy of Abui could be a pattern that is similar to (and perhaps influenced by) verb serialization in Alor Malay. We compared both patterns and did not see a connection between them,
} 
tion is not incredibly salient, it is still found in the community, especially among (pre)adolescents.

\subsection{PAT extension II: Reduplicating with the notion of aimlessness}

As discussed in Sect. 4.2, in Alor Malay, reduplication of verbs marks also aimlessness and casualness, whereas in Abui, the notions of 'aimlessness' and 'casualness' are not found in the verb reduplications of the older speakers. Reduplications by young speakers, however, do express notions such as 'aimlessness' and 'casualness'; for example natea natea 'just standing aimlessly' in (32) and mit $\sim$ mit 'just sitting around aimlessly' in (33). No older speaker reduplicated either of these predicates in response to the same clips.

13-year-old male ((Pre)adolescent)

Wiil neeng natea $\sim$ natea mai he-feela nuku ho-r-i

child man RDP stand COND 3.AL-friend one 3.REC-call.PFV-PFV

'As the child was just standing there [aimlessly], his friend called out to him.'

[SS.13M.47]

(33) 13-year-old female ((Pre)adolescent)

Neeng nuku do mit $\sim$ mit ba langsung laak-e.

man one PROX RDP sit LNK immediately.ML walk-IPFV

'A man is just sitting around [aimlessly]; then walks away.'

[SS.15F.22]

Another example from the corpus is wahai wahai, with the meaning 'look around aimlessly' shown in (34). It is likely that this Abui reduplication is calqued on the Malay reduplication lihat lihat 'look around aimlessly'. For older speakers, wahai wahai does not have that meaning. For them, reduplicating the verb -wahai (together with a pronominal prefix he-) would mean 'staring at [something] continuously'. The man in the clip that triggered the utterance in (34) was looking around, not staring at something.

\section{5-year-old male ((Pre)adolescent)}

Neeng nuku di natea ba wahai $\sim$ wahai

man one 3.AGT stand.IPFV LNK RDP look.at

'A man is standing and looking around (aimlessly).'

[SS.15M.10]

The token frequencies of the PAT extension II discussed here are presented in Table 6. A total of 15/189 (7.9\%) reduplicated forms were used in ways which expressed aimlessness/casualness. (Pre)adolescents used 8/65 (12.3\%) reduplicated forms with the notion of aimlessness/casualness, followed by young adults, $6 / 56(10.7 \%)$, and adults, $1 / 44(2.2 \%)$. Elders did not produce any such forms. This data shows that this type of borrowing is most salient among (pre)adolescents and young adults.

as many Alor Malay serializations encode notions that are different from the notions expressed by the parallel serializations in Abui, and also involve different types of verbs. 
Table 6 Token frequencies for PAT extension II: Borrowing the notion of aimlessness/casualness

\begin{tabular}{lrrr}
\hline Groups & Speakers & $\begin{array}{l}\text { Total number of } \\
\text { reduplications }\end{array}$ & PAT extension II \\
\hline Pre)adolescents & 20 & 65 & $8(12.3 \%)$ \\
Young adults & 17 & 56 & $6(10.7 \%)$ \\
Adults & 15 & 44 & $1(2.2 \%)$ \\
Elders & 8 & 24 & 0 \\
Total & 60 & 189 & $15(7.9 \%)$ \\
\hline
\end{tabular}

\subsection{PAT extension III: Expanding reduplication to new domains}

The previous two sections focused on two specific types of PAT borrowing (in terms of extension), which appear more than twice in the corpus. In addition, there also appeared a large series of reduplications which deviated from the norm, but which did not group together in a significant way. Many of these reduplications are nonce utterances (occuring between once and three times). Therefore, these cases are grouped together in this section and argued to suggest an increased productivity for the process of reduplication.

The examples presented here include instances relating to function and form. In terms of function, we describe nonce instances where reduplication in Abui is used beyond its traditional grammatical domains (see Sect. 4.1). Young Abui speakers are expanding the use of reduplication to replace verbal constructions in a way that is not (yet) acceptable for speakers of the older generation. They also extend reduplication to nouns, which is traditionally not a category that reduplicates in Abui. In terms of form, younger speakers are simplifying the system by ignoring some of the more complex rules regarding which affixes are reduplicated, and simply reduplicate the whole word, analogous to Alor Malay.

In the utterance by a 17-year-old in (35a), the Abui verb karok 'snore' is reduplicated (and its first vowel is also changed from [a] to [o], in resemblance to the Malay word mengorok 'snore'). The reduplication indicates continuity and/or intensity. It was deemed unacceptable by a 40-year-old, who corrected it as in (35b). In the corpus, it occurs several other times as an unreduplicated stem, as in (35c). It is still unclear ${ }^{17}$ why older speakers do not accept this reduplication, while they do accept other reduplicated verbs (Sect. 4.1.1). Thus, the data in (35a-c) provide evidence for the claim that younger speakers use reduplication more productively and to a wider set of verbs than older speakers do.

a. 17-year-old male ((Pre)adolescent)

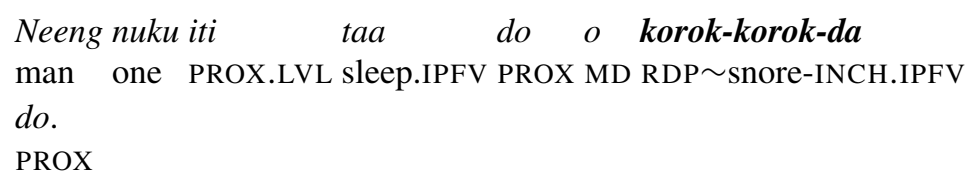

\footnotetext{
${ }^{17}$ It was confirmed with older speakers that it was not the vowel change, but the reduplication that triggered their ungrammaticality judgement.
} 
b. Correction of (35a) by 40-year-old female (Elder)

Neeng nuku taa ba karok-e.

man one sleep LNK snore-IPFV

'A man sleeps and is snoring.'

[FN.40F]

c. 28-year-old male (Adult)

Neeng kalieta nukuiti taa ba karok-e.

man old.person one PROX.LVL sleep.IPFV LNK snore-IPFV

'A man is sleeping and snoring.'

[SS.31M.59]

In (36a), the 17-year-old speaker reduplicates the verb hayeei 'fall from above' to signal that the log that the girl was carrying kept falling (repetition of an event). As shown in (36b) and (36c), a more commonly used construction to express repetition involves using a serial verb construction with the causative verb ong. In (36b), the child causes the log to fall, as evidenced by the subject pronoun $d i$ ' 3 .AGT', whereas in $(36 \mathrm{c})$, the reflexive nonagentive pronoun del triggers an anticausative reading.

a. 17-year-old female ((Pre)adolescent)

...lakaang tihai mai o hayeei hayeei ba iti.

very be.heavy COND MED.DEM RDP fall.from.above LNK lie

'[A girl is pulling a log...] ... because it's very heavy, it finally falls and lies (there).'

[SS.17F.32]

b. Correction of (36a) by 40-year-old female (Elder)

$\begin{array}{lllll}\text {...lakaang tihai mai o di la ong } & \text { di } \\ \text { very be.heavy COND } & \text { MED 3. AGT ADV make }\end{array}$

ha-yeei.

3.PATN-fall.from.above

'... since it's very heavy, she just drops it there.'

c. 43-year-old female (Elder)

[FN.40F]

Moqu nuku oro bataa ha-fik-e.

child one DIST.LVL wood 3.PATN-pull-IPFV

'A child is pulling a log.

Del ong hayeei di ha-fik beeqa.

3.REFL.NAGT make fall.from.above 3.AGT 3.PATN-pull cannot

It falls, and she can't pull it (anymore).'

[SS.43F.25]

The corrections in (35b) and (36b) to the examples (35a) and (36a), respectively, show that younger speakers are expanding the verb reduplication pattern to replace other existing verbal constructions. They are extending the existing function of intensity and iterativity on new verbs. Older speakers do not accept all the reduplications that young speakers produce.

In addition to applying reduplication to verbs, young speakers also extend reduplication to the nominal domain. The corpus contains two instances of reduplicated Abui nouns (37a-b), both uttered by young speakers. The reduplication neeng $\sim$ neeng 'men' may have been created partly analogous to Alor Malay laki laki 'man; men', which can have both a singular and a plural interpretation. The reduplication of maayol maayol 'women' is meant to mark plurality; the Malay equivalent would 
be perempuan perempuan 'women'. By contrast, (37c) shows an adult's use of the plural word loqu, which is the default Abui strategy for marking plurality.

a. Reduplication of nouns; 14-year-old female ((Pre)adolescent)

Neeng $\sim$ neeng, ya maayol maayol o

$\mathrm{RDP} \sim \operatorname{man}$ and $\mathrm{RDP} \sim$ woman DEM.MED

doo-ha-yok.

3.REFL.GOAL-3.PATN-shake

'Men and women are dancing.'

[SS.14F.15]

b. Reduplication of nouns; 24-year-old male (Young adult)

Neeng $\sim$ neeng maayol $\sim$ maayol del

$\mathrm{RDP} \sim \operatorname{man} \quad \mathrm{RDP} \sim$ woman 3. REFL.NAGT

to-wal-ri

DISTR.REC-be.like-reach.PFV

ba doo-ha-yok-e.

LNK 3.REFL.GOAL-3.PATN-shake-IPFV

'Men and women are gathered together and dancing.' [SS.24M.40]

c. Use of plural word; 32-year-old (Adult)

Neeng ya maayol loqu doo-ha-yok-e

man and woman PL 3.REFL.REC-3.PATN-shake-IPFV

'Men and women are dancing.'

[SS.32M.60]

An additional non-verb reduplication attested in young speakers is nuku nuku 'one by one' in (38). This form is likely to be a calque from Malay satu $\sim s a t u$ 'one by one' (see (28). Although Abui can reduplicate cardinal numerals to derive distributive numerals (Klamer et al. 2017:348-349), as shown in (38c) (as well as in (12)), the generally accepted form of the distributive of 'one' takes an irregular short form $n u k$ of the root nuku 'one', and must involve the aspectual suffix -dal-di. By contrast, the reduplication of the young speaker in (38a) just copies the regular form nuku 'one', without additional affixes.

a. 16-year-old female

Ara nuku nuku, nuku-nuku he-fanga.

try $\mathrm{RDP} \sim$ one $\mathrm{RDP} \sim$ one 3.LOC-speak.IPFV

'Try (it) one by one, say it one by one.'

[CV.16F.DA]

b. Correction by 40-year-old female

Ara $\boldsymbol{n u k} \sim \boldsymbol{n u k}$-di ba he-fanga.

try $\mathrm{RDP} \sim$ one-INCH.PFV LNK 3.REC-speak.IPFV

'Try to say it one by one.'

[FN.40F]

c. 27-year old female

Meting ba taha tel ametaba rifi $\quad \boldsymbol{n u k} \sim \boldsymbol{n u k}-d a$ betel.vine REL on.top tie small LNK thousand RDP one-INCH.IPFV yo.

MED.ADDR

'The betel vine that you tie [in] small [bunches] which [sell for] 1000 per piece...'

[CV.27F.GJ] 
Table 7 Token frequencies for PAT extension III: Expanding reduplication to new domains

\begin{tabular}{lrrr}
\hline Groups & Speakers & $\begin{array}{l}\text { Total number of } \\
\text { reduplications }\end{array}$ & PAT extension III \\
\hline (Pre)adolescents & 20 & 65 & $6(9.2 \%)$ \\
Young adults & 17 & 56 & $3(5.4 \%)$ \\
Adults & 15 & 44 & $1(2.2 \%)$ \\
Elders & 8 & 24 & 0 \\
Total & 60 & 189 & $10(18.9 \%)$ \\
\hline
\end{tabular}

In this section, we have seen various instances of nonce reduplication. The most notable ones included an increased productivity on verbs, an expansion of reduplication to the domain of nouns, and the use of total reduplication on numerals, instead of stem reduplication. The token frequencies for a combined total of all the deviant reduplications of types discussed in this section are listed in Table 7. (Pre)adolescents produced 6/65 (9.2\%) such tokens, followed by young adults, 3/17 (5.4\%), and adults, $1 / 44(2.2 \%)$. All of these instances were shown not to be acceptable for speakers of the older generation. This suggests that (pre)adolescents are most likely to exhibit this kind of change, followed more moderately by young adults and to a much lesser extent adults. We analyze this as an extension of the reduplicative pattern already present in Abui, under the influence of Alor Malay.

\subsection{Lexical borrowing as a gateway to Malay reduplications}

Broadly speaking, Abui speakers of all age groups insert Malay words, ranging from verbs to discourse markers. However, only in the younger group (mostly (pre)adolescents and young adults) does the set of Malay insertions also include reduplications. Two Malay reduplications frequently inserted by younger speakers are the adverbs tiba tiba 'suddenly' (from the base form tiba 'arrive') ${ }^{18}$ and sama $\sim$ sama 'together' (from the base word sama 'with; same'). ${ }^{19}$ (In the examples below, the insertions are marked in bold.) Both reduplications are treated as adverbs when inserted into Abui; however, sama sama 'together' is occasionally also treated as a verb. In (39), the Alor Malay loan tiba-tiba occurs in the adverbial slot, before the subject pronoun $d i$ '3.AGT'.

\footnotetext{
${ }^{18}$ As pointed out by František Kratochvíl (p.c.), even in Malay, tiba tiba is a lexicalized form and native speakers are probably not aware of the derivation link between tiba and tiba tiba, suggesting that is probably inserted as one chunk.

${ }^{19}$ The base form sama 'same' has also been borrowed into Abui and is used by older speakers. It appears to be fully integrated into Abui and it differs suprasegmentally from Malay sama 'same'. In the Abui sama [sa'ma:], the second syllable is prominent, while in Malay ['sa:ma], the first syllable is prominent (thanks to František Kratochvíl for pointing this out). The borrowing of sama has probably happened at an earlier stage than the reduplicated form, especially since most adult speakers do not consider Abui sama 'same' to be a Malay word, whereas they flag sama sama immediately as a Malay insertion, indicative of young people's speech.
} 
25-year-old male (Young adult)

Oro $\quad n u=n g \quad$ we tiba $\sim$ tiba di kaberang-di.

DIST.LVL DIST=ALLA go suddenly.MLY 3.AGT trip-INCH.PFV

'[He was] going there; suddenly, he tripped.'

[SS.25M.43]

Examples (40)-(42) illustrate the insertion of sama sama 'together' ${ }^{20}$ In (40), sama sama is treated as an adverbial, modifying laak 'walk'. In (41) and (42), younger speakers combine sama sama with a pronominal quantifier -tafuda 'all' to derive the sense 'altogether'.

27-year-old-female (Adult)

Moqu loqu nu hel mi=se sama sama laak. child PL DIST 3.NAGT take=PRIOR together.MLY walk

'Those children, pick them up and walk together.'

[CV.27F.GJ]

(41) 24-year-old male (Young adult)

Moqu loqu faaring ya pi-muknehi George baai

child PL many and 1PL.INCL.AL-same.sex.relative George also

nutafuda sama-sama we-i hare...

1PL.EXCL.ALL together.MLY go-PFV so

'Many kids and our brother George as well, we all went together, so ...'

[CV.24M.BC]

(42) 22-year-old female (Young adult)

Putafuda sama $\sim$ sama-di ba yai paneng naha.

1PL.INCL.ALL together.MLY-INCH.PFV LNK song make NEG

'We all can't come and sing together!'

[CV.22F.OG]

The form sama sama is typically not found in older speakers' speech. When older speakers are presented with sentences such as (40)-(42) containing sama $\sim$ sama, they often reject it and construct a new sentence only containing the pronominal quantifier -tafuda 'ALL', as in (43).

40-year-old female (Elder)

Putafuda yai paneeng naha!

1PL.INCL.ALL song make NEG

'We can't all sing together!'

[CV.22F.OG]

In addition, this is also reflected when they express the sense 'altogether' by using -tafuda 'ALL' on its own, as shown in (44).

40-year-old (Elder)

Nutafuda hel fala nu=ng taa.

1PL.EXCL.ALL ART house DIST=ALLA sleep.IPFV

'We (excl.) slept in that house altogether.'

(Kratochvíl corpus)

\footnotetext{
${ }^{20}$ Malay sama sama 'together' can also be used in other contexts, such as in responses to terima kasih 'thank you'. It does not seem to be used in Abui in this particular sense.
} 
The categorization of sama sama in Abui varies. Often, it is treated as an adverbial, with no morphology and occurring before the verb, as in (40) and (41). Sometimes, however, it is treated as a verb, as in (42), where it takes the inchoative perfective suffix - $d i$ that is commonly indicative of a derived verb. It also occurs in clause-final position, which is typical for verbs, preceding the clause linker $b a$. Examples (45) and (46) illustrate two nonce insertions (occurring 1-3 times in the corpus). In (45a), a (pre)adolescent speaker inserts teman teman 'RDP friend' into an Abui nominal construction; compare Alor Malay (45b) and Abui (45c). In Abui, nominals cannot be reduplicated, as shown by the ungrammatical phrase between brackets in (45c).

a. Abui with Alor Malay loan reduplication: 12-year-old female

((Pre)adolescent)

e-teman teman loqu

2SG.AL-RDP friend.MLY PL

'your friends'

[CV.12F.MM]

b. Alor Malay: 40-year-old female (Elder)

lu pung teman $\sim$ teman dong

2SG POSS RDP friend PL

'your friends'

c. Abui: 40-year-old female (Elder)

e-feela loqu (*e-feela $\sim$ feela loqu

2SG.AL-friend PL

'your friends'

[FN.40F]

Another example is senyum senyum 'smile continuously/with no aim' (from senyum 'smile') in (46). The verb senyum 'smile' does not have a direct equivalent verb in Abui. This lexical gap could be a plausible explanation for the this lexical borrowing into Abui.

27-year-old male (Adult)
Wiil neeng nuku iti $\quad$ de-wiil
child man one PROX.LVL 3 -REFL.AL-CHILD 3.PATN-cradle LNK
natet
stand.PFV
haba la senyum $\sim$ senyum ba natet do
but ADV RDP $\sim$ smile LNK stand.PFV PROX

'A young man is cradling his child and standing but he's smiling for no reason and standing.'

[SS.27M.56]

The token frequencies of loan reduplications are listed in Table 8. These counts include the widespread insertions sama $\sim$ sama 'together' and tiba $\sim t i b a$ 'suddenly' as well as full nonce reduplications (of verbs, nouns, and other parts-of-speech) that are directly transferred from Alor Malay. (Pre)adolescents and young adults have similar tokens: $16 / 65$ (25\%) vs. 13/56 (23\%), while adults have 5/44 (11\%) and elders have 0 . More specifically, (pre)adolescents favor sama $\sim$ sama insertions as well as nonce insertions, while young adults favor sama sama, and tiba tiba. 
Table 8 Token frequencies of loan reduplications, produced by $\mathrm{N}$ speakers

\begin{tabular}{|c|c|c|c|c|c|}
\hline \multirow[t]{2}{*}{ Groups } & \multirow[t]{2}{*}{$\mathrm{N}$ of Speakers } & \multirow[t]{2}{*}{$\begin{array}{l}\text { Total number of } \\
\text { reduplications }\end{array}$} & \multicolumn{3}{|c|}{$\begin{array}{l}\text { Loan } \\
\text { reduplications }\end{array}$} \\
\hline & & & sama $\sim$ sama & tiba $\sim$ tiba & Nonce \\
\hline \multirow[t]{2}{*}{ (Pre)adolescents } & 20 & 65 & & $16(25 \%)$ & \\
\hline & & & 5 & 0 & 11 \\
\hline \multirow[t]{2}{*}{ Young adults } & 17 & 56 & & $13(23 \%)$ & \\
\hline & & & 7 & 6 & 0 \\
\hline \multirow[t]{2}{*}{ Adults } & 15 & 44 & & $5(11 \%)$ & \\
\hline & & & 2 & 1 & 2 \\
\hline \multirow[t]{2}{*}{ Elders } & 8 & 24 & & 0 & \\
\hline & & & 0 & 0 & 0 \\
\hline \multirow[t]{2}{*}{ Total } & 60 & 189 & & 34 & \\
\hline & & & 14 & 7 & 13 \\
\hline
\end{tabular}

\subsection{Summary of token frequencies}

Section 4.1 has described Abui 'native' patterns of reduplication found in older speakers. Sections 6.1-6.4 described instances of contact-induced reduplications, which included three types of PAT extension and some instances of loan reduplications, which are lexical borrowings. Table 9 summarizes the token frequencies found in each of these categories. It displays the total number of reduplications per group, and lists the number of native reduplications as well as the instances of contact-induced reduplications.

The column 'native reduplications' shows that there is positive correlation with age: (pre)adolescents produced $31 / 65(47 \%)$ native reduplications, followed by young adults, 33/56 (59\%), adults, 36/44 (82\%), and elders, 24/24 (100\%).

Table 9 Summary of total token frequencies for reduplicated words

\begin{tabular}{|c|c|c|c|c|c|c|c|}
\hline \multirow[t]{3}{*}{ Groups } & \multirow[t]{3}{*}{ Speakers } & \multirow{3}{*}{$\begin{array}{l}\text { Total number of } \\
\text { reduplications }\end{array}$} & \multirow{3}{*}{$\begin{array}{l}\text { Native } \\
\text { reduplications }\end{array}$} & \multicolumn{4}{|c|}{ Contact-induced reduplications } \\
\hline & & & & \multicolumn{3}{|c|}{ Pattern extension } & \multirow{2}{*}{$\begin{array}{l}\text { Loan } \\
\text { reduplications }\end{array}$} \\
\hline & & & & PE1 & PE2 & PE3 & \\
\hline \multirow[t]{2}{*}{ (Pre)adolescents } & 20 & 65 & $31 / 65(47 \%)$ & $18 / 65$ & $(28 \%$ & & $16 / 65(25 \%)$ \\
\hline & & & & 4 & 8 & 6 & \\
\hline \multirow[t]{2}{*}{ Young adults } & 17 & 56 & $33 / 56(59 \%)$ & $10 / 56$ & $(18 \%$ & & $13 / 56(23 \%)$ \\
\hline & & & & 1 & 6 & 3 & \\
\hline \multirow[t]{2}{*}{ Adults } & 15 & 44 & $36 / 44(82 \%)$ & $3(7 \%$ & & & $5 / 44(11 \%)$ \\
\hline & & & & 1 & 1 & 1 & \\
\hline \multirow[t]{2}{*}{ Elders } & 8 & 24 & $24 / 24(100 \%)$ & 0 & & & 0 \\
\hline & & & & 0 & 0 & 0 & \\
\hline \multirow[t]{2}{*}{ Total } & 60 & 189 & 124 & 31 & & & 34 \\
\hline & & & & 6 & 15 & 10 & \\
\hline
\end{tabular}


Looking now at the category of contact-induced reduplications, with regards to PAT extension (combining the three types), (pre)adolescents show a higher proportion compared to young adults: 18/65 (28\%) vs. 10/56 (18\%). Adults had 5/44 (11\%) tokens of loan reduplications and 3/44 (7\%) tokens of PAT borrowing, while elders had 0 tokens of either. Regarding loan reduplications, (pre)adolescents and young adults have similar tokens: 16/65 (25\%) vs. 13/56 (23\%).

\section{Summary and discussion}

Verbal reduplication exists in both Alor Malay and the Abui of elder speakers, encoding intensity, continuity, and repetition. However, reduplication is used much more elaborately and productively in Alor Malay than in Abui. While Alor Malay reduplicates nouns, verbs, adverbs, adjectives, question words and numerals, Abui reduplicates only (stative) verbs, question words, and numerals. In addition, there are restrictions on Abui verbal reduplication that do not apply in Alor Malay: to encode intensity, some Abui verbs must feature alongside another verb in a parallel serial verb construction; in Alor Malay, any verb can be reduplicated. Furthermore, Alor Malay allows for a broader set of semantic notions to be expressed through reduplication, such as casualness/aimlessness.

Comparing the reduplication patterns of (pre)adolescents, young adults, adults with those of elders, it is observed that (pre)adolescents and young adults in particular appear to be expanding the system in four ways: 1) They use verb reduplications instead of parallel serializations, 2) They extend the semantic notions encoded by reduplications to include casualness/aimlessness, 3) They use reduplication more productively on verbs and in some cases, also reduplicate items from other parts-ofspeech, 4) They tend to use more loan reduplication from Alor Malay. The outcome observed in our study involves both the borrowing of morphological patterns and the borrowing of lexical material, and more specifically PAT extension, whereby 'an existing pattern spreads to a wider range of contexts' (Backus et al. 2011:743) in the younger generation. Adults display very few of these tendencies, but generally behave like elders.

We described three types of PAT borrowing which all involved extending the reduplication pattern into new domains. Judgements by elder speakers as well as utterances from them were used as evidence that these are indeed emerging patterns, previously not in use. (Pre)adolescents were seen to be most engaging in PAT borrowing, followed by young adults, and then by adults. (Pre)adolescents also tend to use more loan reduplications from Alor Malay. The most salient type of PAT borrowing taking place in all three groups is the exploitation of the notion of casualness and aimlessness for reduplications.

We argue that PAT borrowing may be accelerated by lexical borrowing. It is noteworthy that both cases of nonce instances lexical borrowing (one to mark plurality, the other to express casualness/aimlessness) are also attested as PAT borrowing. That lexical borrowing can accelerate PAT borrowing, has been shown for other languages as well, such as Imbabura Quechua where the borrowing of Spanish conjunctions has triggered the use of subordinate clauses, as in Spanish, instead of nominalized constructions, as expected in Quechua (Gómez-Rendón 2007:501-502). 
In a contact scenario, speakers do not necessarily introduce completely new structures borrowed from a source language, but tend to build on structures which already exist in their native language (cf. Law 2020; Mithun 2020; Ralli 2020; Souag 2020). In other words, PAT borrowing often involves an adaptation in the frequency distribution of patterns that already existed in the recipient language (SilvaCorvalán 1993, 1994, 2008). This adaptation in frequency has been referred to as a 'system-preserving change', as it involves a restructuring of the system, altering "the way in which a [shared and existing] category is expressed" (Backus 2004:180). A 'shared' category may share some parameters across two languages, but may also have some important underlying differences, as in the case of reduplication in Alor Malay and the Abui of older speakers. Backus et al. (2011) argue that a construction that initially shows a small amount of overlap with a source language, may very easily expand its usage further and thus gain a larger amount of overlap due to contact. For example, using a subject-verb-object word order in German subordinate clauses (which normally have subject-object-verb order) is common in informal styles of German, but due to the influence of English on the German variety spoken in Australia, it has become the standard order for subordinate clauses in Australian German (Clyne 2003:132-135).

A similar process of expansion is argued here to explain why younger Abui speakers extend their reduplication system to i) include verbs that would normally only be serialized to mark intensity, ii) add the notion of casualness, and iii) reduplicate verbs and nouns that normally would not be reduplicated. That is, when speakers find evidence for a construction that is shared among the source and recipient language, that structure is likely to show an increase in frequency in the recipient language, in addition to becoming more entrenched and more productive (Backus 2004). Furthermore, as pointed out in Sect. 4.2, reduplication in Alor Malay may have multiple functions, sometimes even marking seemingly opposite ones. The fact that younger speakers are encoding casualness/aimlessness in addition to intensity (based on context) is evidence that they are transferring this flexibility from Alor Malay to Abui. This may be considered a form of complexification of Abui.

While incorporating the notion of casualness/aimlessness may be seen as a form of complexification, there are also ways in which the reduplication system is undergoing simplification. For example, reduplication in Abui, by being less productive than it is in Alor Malay poses more restrictions for speakers. It appears to be lexically based to some extent, so speakers have to learn which verbs may or may not be reduplicated. In addition, there are subtle rules governing form, suffixes are not reduplicated, except for the patientive paradigm. Younger speakers appear to be simplifying the system by expanding the inventory of verbs which may be reduplicated and by choosing to ignore formal rules, by simply using total reduplication. The fact that both complexification and simplification are taking place (in different domains) is not uncommon (Trudgill 2011:15-61).

The occurrence of reduplication on different parts-of-speech, such as nouns and verbs might offer a window into entrenchment and productivity. On the model of Alor Malay, reduplication first expands in the domain of verbs, reinforcing a pattern that already existed in Abui. By constrast, nouns are still only slightly affected, as Abui traditionally does not have noun reduplication. This suggests that the emergent 
contact-induced change discussed in this article, in first place, affects and expands the verbal domain where structural overlap obtains, while initially not affecting the nominal domain where no structural overlap exists. However, the nonce loan reduplications could suggest that, after verbal reduplication is expanded, nominal reduplication might be next in line.

In addition to these tendencies involving PAT extension, several other factors must be mentioned in explaining the contact scenario under scrutiny. As shown by Ansaldo and Matthews (2004), Bakker and Parkvall (2005), Evans (2009), Reid (2009), Wee and Lim (2004), reduplication is a morphological operation that is often borrowed through contact. As mentioned in Sect. 1, other Alor-Pantar languages, such as Kafoa and Reta, have also been reported to be subject to transfer effects from Alor Malay with respect to the marking of plurality and casualness/aimlessness, respectively (Baird 2017; Willemsen 2020). It is thus unsurprising that this change has affected Abui, as well. If this is indeed the case, future studies could investigate more AlorPantar languages and observe whether Alor Malay is affecting their reduplication systems in similar ways.

As a crosslinguistically common morphological operation (Rubino 2013), reduplication has been cited as being one of the universal basic combinatory principles governing improvised language behavior (Muysken 2013). This suggests that it is rather prominent in scenarios involving incomplete acquisition and is salient in pidgins and creoles. Bakker and Parkvall (2005) list a number of hypotheses explaining the prevalence of reduplication in creoles. Besides the obvious iconic property of reduplication, they argue that reduplication arises in the pidgin phase. Due to the limited lexicon of a pidgin, communicative pressure might force the lexicon to expand. In addition to lexical borrowing (which Abui speakers also do), another efficient method is to introduce a morphological process to derive new meanings. Therefore, taken together, the new Abui reduplication patterns are likely to be the result of a combination of contact-induced change and universal word formation strategies. These different factors cannot be easily disentangled and are argued to all play a role in explaining the phenomena studied here.

\section{Conclusion}

In Abui, both morphological PAT borrowing and lexical borrowing are argued to be a form of emergent contact-induced change. These changes are not completed yet and they are merely present in a few constructions. Similar to what Backus et al. (2011) found for Turkish-Dutch contact, emergent contact-induced change in reduplication in the Abui context is argued to be favored by the bilingualism setting at play: Abui has been in stable contact with Malay for roughly 50 to 60 years, and especially the groups of (pre)adolescents and young adults now consider Malay to be their dominant language. Future follow-up studies of the same population should investigate whether the variation of today will have lead to language change.

\section{Abbreviations}

Glossing conventions follow the Leipzig rules (https://www.eva.mpg.de/lingua/pdf/ Glossing-Rules.pdf), plus the following: ADV: adverbial, AGT: agentive pronoun, 
AL: alienable possessive, ALL: 'all' pronoun, ALLA: allative, ALONE: 'alone' pronoun, APPL: applicative, ART: article, ASSOC: associative plural, COND: conditional, DIST: distal demonstrative, DISTR: distributive, DIST.LVL: distal level elevational, EMPH: emphatic, EXT: existential, EXCLM: exclamative, FOC: focus pronoun, GOAL: goal pronominal marker, INAL: inalienable possessive, INCH: inchoative, LNK: clause linker, LOC: locative pronominal marker, LOCA: locative preposition, MED: medial demonstrative, MED.ADDR: medial addressee demonstrative, MLY: Malay word, NAGT: nonagentive pronoun, NEG: negation, PATN: patientive pronominal marker, PL: plural marker, PRO: pronominal, PROG: progressive, PROX: proximal, REC: recipient argument marker, REFL: reflexive, REL: relativizer, RDP: reduplication, STAT: stative, TAG: tag question.

Abbreviations used in the examples' source code: CV: conversational data, FN: fieldnotes, SS: Surrey Stimuli data; F: female speaker, M: male speaker.

Acknowledgements This research was supported by the VICI research project 'Reconstructing the past through languages of the present: the Lesser Sunda Islands' at Leiden University, awarded to Marian Klamer and funded by the Netherlands Organisation for Scientific Research (NWO), project number 27770-012. We would like to acknowledge the expertise, assistance, and hospitality, of the Abui speech community in Takalelang, Alor, without whom none of this work would have been possible. Special thanks go to Dori Lanma, Simon Lanma, Ansel Delpada, Frengki Delpada, and Benny Delpada. We would also like to thank František Kratochvíl for offering valuable information with regards to reduplication in Abui. Thanks also to the volume editor Francesco Gardani and two anonymous reviewers for valuable comments and feedback. Any remaining errors are our own.

Author contribution Data collection and transcription was done by George Saad. Both authors contributed equally to the analysis of the data and writing of the paper, and they are listed alphabetically.

Publisher's Note Springer Nature remains neutral with regard to jurisdictional claims in published maps and institutional affiliations.

Open Access This article is licensed under a Creative Commons Attribution 4.0 International License, which permits use, sharing, adaptation, distribution and reproduction in any medium or format, as long as you give appropriate credit to the original author(s) and the source, provide a link to the Creative Commons licence, and indicate if changes were made. The images or other third party material in this article are included in the article's Creative Commons licence, unless indicated otherwise in a credit line to the material. If material is not included in the article's Creative Commons licence and your intended use is not permitted by statutory regulation or exceeds the permitted use, you will need to obtain permission directly from the copyright holder. To view a copy of this licence, visit http://creativecommons.org/licenses/by/4.0/.

\section{References}

Adelaar, K. A., \& Prentice, D. J. (with contributions from C. D. Grijns, H. Steinhauer, \& A. van Engelenhoven) (1996). Malay: Its history, role and spread. In S. A. Wurm, P. Mühlhäusler, \& D. T. Tryon (Eds.), Atlas of languages of intercultural communication in the Pacific, Asia, and the Americas, vol. 2: Texts (pp. 673-693). Berlin: Mouton De Gruyter. https://doi.org/10.1515/9783110819724.2.673.

Ansaldo, U., \& Matthews, S. (2004). The origins of Macanese reduplication. In G. Escure \& A. Schwegler (Eds.), Creoles, contact and language change: Linguistic and social implications (pp. 1-19). Amsterdam/Philadelphia: John Benjamins.

Backus, A. (2004). Convergence as a mechanism of language change. Bilingualism: Language and Cognition, 7(2), 179-181. https://doi.org/10.1017/S1366728904001567.

Backus, A., Seza Doğruöz, A., \& Heine, B. (2011). Salient stages in contact-induced grammatical change: Evidence from synchronic vs. diachronic contact situations. Language Sciences, 33(5), 738-752. https://doi.org/10.1016/j.langsci.2011.02.004. 
Baird, L. (2017). Kafoa. In A. Schapper (Ed.), The Papuan languages of Timor, Alor, and Pantar (Vol. 2, pp. 55-108). Boston/Berlin: Mouton De Gruyter.

Baird, L., Klamer, M., \& Kratochvíl, F. (n.d.). Alor Malay: A grammar sketch. Leiden University/Palacký University Olomouc

Bakker, P., \& Parkvall, M. (2005). Reduplication in pidgins and creoles. In B. Hurch \& V. Mattes (Eds.), Studies on reduplication (pp. 511-531). Berlin: Mouton de Gruyter.

Baron van Lynden, D. W. C. (1851). Bijdrage tot de kennis van Solor, Allor, Rotti, Savoe en omliggende eilanden. Natuurkundig Tijdschrift voor Nederlandse Indië, 2, 317-336.

Blust, R. (2013). The Austronesian languages (2nd ed.). Canberra: Pacific Linguistics.

Clyne, M. C. (2003). Dynamics of language contact: English and immigrant languages. Cambridge: Cambridge University Press.

Delpada, B. (2016). Abui phonology. MA thesis. Singapore: Nanyang Technological University.

Du Bois, C. (with analyses by A. Kardiner \& E. Oberholzer) (1944). The people of Alor: A socialpsychological study of an East Indian island. Minneapolis: University of Minnesota Press.

Eades, D. (2005). A grammar of Gayo: A language of Aceh, Sumatra. Canberra: Pacific Linguistics.

Evans, N. (2009). Doubled up all over again: Borrowing, sound change and reduplication in Iwaidja. Morphology, 19(2), 159-176.

Fedden, S., Brown, D., \& Corbett, G. G. (2010). Conditions on pronominal marking: A set of 42 video stimuli for field elicitation. University of Surrey. https://doi.org/10.15126/SMG.25/1.

Gardani, F. (2018). On morphological borrowing. Language and Linguistics Compass, 12(10), 1-17. https://doi.org/10.1111/lnc3.12302.

Gardani, F. (2020). Borrowing matter and pattern in morphology. An overview. Morphology.

Gil, D., \& Hurch, B. (2005). From repetition to reduplication in Riau Indonesian. In B. Hurch (Ed.), Studies on reduplication (pp. 31-64). Berlin: Mouton De Gruyter.

Gomang, S. R. (1993). The people of Alor and their alliances in eastern Indonesia: A study in political sociology. Thesis, University of Wollongong MA (Hons.).

Gómez-Rendón, J. (2007). Grammatical borrowing in Imbabura Quichua (Ecuador). In Y. Matras \& J. Sakel (Eds.), Grammatical borrowing in cross-linguistic perspective (pp. 481-522). Berlin: Mouton de Gruyter.

Grenoble, L. A., \& Whaley, L. J. (2006). Saving languages: An introduction to language revitalization. Cambridge: Cambridge University Press.

Heine, B., \& Kuteva, T. (2005). Language contact and grammatical change. Cambridge: Cambridge University Press.

B. Hurch (Ed.). (with editorial assistance of V. Mattes) (2005). Studies on reduplication. Berlin: Mouton de Gruyter.

Jacob, J., \& Grimes, C. E. (2003). Kamus pengantar Bahasa Kupang - Bahasa Indonesia (dengan daftar Indonesia - Kupang) (2nd ed.). Kupang, Indonesia: Artha Wacana Press.

Kiyomi, S. (2009). A new approach to reduplication: A semantic study of noun and verb reduplication in the Malayo-Polynesian languages. Linguistics, 33(6), 1145-1168.

Klamer, M., Schapper, A., Corbett, G., Holton, G., Kratochvíl, F., \& Robinson, L. C. (2017). Numeral words and arithmetic operations in the Alor-Pantar languages. In M. Klamer (Ed.), The Alor-Pantar languages: History and typology (2nd ed., pp. 329-364). Berlin: Language Science Press.

Kluge, A. J. H. (2014). A grammar of Papuan Malay. PhD dissertation, Leiden University.

Kratochvíl, F. (2007). A grammar of Abui: A Papuan language of Alor. PhD dissertation, Leiden University.

Kratochvíl, F. (2011). Transitivity in Abui. Studies in Language, 35(3), 588-635.

Kratochvíl, F. (2014a). Differential argument realization in Abui. Linguistics, 52(2), 543-602. https://doi.org/10.1515/ling-2013-0072.

Kratochvíl, F. (2014b). Number in Abui and Sawila. In M. Klamer \& F. Kratochvíl (Eds.), Number and quantity in East Nusantara (pp. 123-151). Canberra: Asia-Pacific Linguistics.

Kratochvíl, F., \& Delpada, B. (2019). The role of the lexicon in aspectuality in Abui. Unpublished manuscript.

Law, D. (2020). Pattern borrowing, linguistic similarity, and new categories: Numeral classifiers in Mayan. Morphology. https://doi.org/10.1007/s11525-020-09361-7.

Li, Y., \& Ponsford, D. (2018). Predicative reduplication: Functions, their relationships and iconicities. Linguistic Typology, 22(1), 51-118.

Matras, Y., \& Sakel, J. (2007). Investigating the mechanisms of pattern replication in language convergence. Studies in Language, 31(4), 829-865. 
Mattes, V. (2007). Types of reduplication: A case study of Bikol. $\mathrm{PhD}$ dissertation, Karl-FranzensUniversität Graz.

Mithun, M. (2020). Replicated inflectional matter? Plots twists behind apparent borrowed plurals. Morphology. https://doi.org/10.1007/s11525-020-09351-9.

Moravcsik, E. (1974). Reduplicative constructions. In J. H. Greenberg (Ed.), Universals of human language, vol. 3: Word structure (pp. 297-334). Stanford: Stanford University Press.

Moravcsik, E. (2013). Introducing language typology. Cambridge: Cambridge University Press.

Muysken, P. (2013). Language contact outcomes as the result of bilingual optimization strategies. Bilingualism: Language and Cognition, 16(4), 709-730.

Nagy, N. (2009). The challenges of less commonly studied languages: Writing a sociogrammar of Faetar. In J. N. Stanford \& D. R. Preston (Eds.), Variation in indigenous minority languages (pp. 397-418). Amsterdam/Philadelphia: John Benjamins.

Paauw, S. H. (2008). The Malay contact varieties of eastern Indonesia: A typological comparison. $\mathrm{PhD}$ dissertation, State University of New York, Buffalo.

Perono Cacciafoco, F., Cavallaro, F., \& Kratochvíl, F. (2015). Diachronic toponomastics and language reconstruction in South-East Asia according to an experimental convergent methodology: Abui as a case-study. Review of Historical Geography and Toponomastics, 10, (19-20), 29-47.

Ralli, A. (2020). Matter versus pattern borrowing in compounding: Evidence from the Asia Minor Greek dialectal variety. Morphology.

Reid, L. A. (2009). On the diachronic development of C1V1 reduplication in some Austronesian languages. Morphology, 19(2), 239-261.

Rubino, C. (2005). Reduplication: Form, function and distribution. In B. Hurch (Ed.), Studies on reduplication (pp. 11-29). Berlin: Mouton De Gruyter.

Rubino, C. (2013). Reduplication. In M. S. Dryer \& M. Haspelmath (Eds.), The World Atlas of Language Structures Online, Leipzig: Max Planck Institute for Evolutionary Anthropology. http://wals.info/chapter/27.

Saad, G. (2019a). Abui corpus. In M. Klamer, H. Fricke, F. Moro, G. Saad, \& E. Visser (Eds.), Language collection "Eastern Indonesia and Timor Leste”. https://hdl.handle.net/1839/ 06afa50e-aee9-4adb-a6a7-d7496a8a47fc.

Saad, G. (2019b). Alor Malay corpus. In M. Klamer, H. Fricke, F. Moro, G. Saad, \& E. Visser (Eds.), Language collection "Eastern Indonesia and Timor Leste”. https://hdl.handle.net/1839/ 06afa50e-aee9-4adb-a6a7-d7496a8a47fc.

Saad, G. (2020a). Variation and change in Abui: The impact of Alor Malay on an indigenous language of Indonesia. PhD dissertation, Leiden University.

Saad, G. (2020b). Abui. In A. Schapper (Ed.), The Papuan languages of Timor, Alor and Pantar (Vol. 3, pp. 267-346). Boston/Berlin: Mouton De Gruyter. https://doi.org/10.1515/9781501511158-005.

Saad, G., Klamer, M., \& Moro, F. (2019). Identifying agents of change: Simplification of possessive marking in Abui-Malay bilinguals. Glossa: A journal of general linguistics, 4(1), 1-29. https://doi.org/10.5334/gjgl.846.

Schapper, A. (2017). Introduction. In A. Schapper (Ed.), The Papuan languages of Timor, Alor, and Pantar (Vol. 2, pp. 185-266). Boston/Berlin: Mouton De Gruyter.

Silva-Corvalán, C. (1993). On the permeability of grammars: Evidence from Spanish and English contact. In W. J. Ashby, M. Mithun, G. Perissinotto, \& E. Raposo (Eds.), Selected papers from the 21st symposium on Romance languages (pp. 19-43). Amsterdam/Philadelphia: John Benjamins.

Silva-Corvalán, C. (1994). Language contact and change: Spanish in Los Angeles. Oxford: Clarendon Press.

Silva-Corvalán, C. (2008). The limits of convergence in language contact. Journal of Language Contact, 2(1), 213-224.

Sneddon, J. N., Adelaar, A. K., Djenar, D. N., \& Ewing, M. (2012). Indonesian: A comprehensive grammar (2nd ed.). London: Routledge.

Souag, L. (2020). When is templatic morphology borrowed? On the spread of the Arabic elative. Morphology. https://doi.org/10.1007/s11525-020-09360-8.

Steinhauer, H. (2014). Blagar. In A. Schapper (Ed.), The Papuan languages of Timor, Alor and Pantar (Vol. 1, pp. 147-220). Boston/Berlin: Mouton De Gruyter.

Tadmor, U. (2009). Malay-Indonesian. In B. Comrie (Ed.), The world's major languages (2nd ed.). London: Routledge.

Trudgill, P. (2011). Sociolinguistic typology: Social determinants of linguistic complexity. Oxford: Oxford University Press. 
Wee, L., \& Lim, L. (2004). Reduplication and discourse particles. L. Lim (Ed.). Singapore English: A grammatical description (pp. 105-126). Amsterdam/Philadelphia: John Benjamins.

Willemsen, J. (2020). Reta. In A. Schapper (Ed.), The Papuan languages of Timor, Alor, and Pantar (Vol. 3 , pp. 187-266). Boston/Berlin: Mouton De Gruyter.

Yanti, \& Raimy, E. (2010). Reduplication in Tanjung Raden Malay. In R. Mercado, E. Potsdam, \& L. deMena Travis (Eds.), Austronesian and theoretical linguistics (pp. 25-44). Amsterdam/Philadelphia: John Benjamins. 